\title{
GEOGRAFÍA LINGÜÍSTICA DEL JUDEOESPAÑOL DE ACUERDO CON EL LÉXICO*
}

\author{
ALdina QUINTANA \\ Universidad Hebrea de Jerusalén
}

\section{INTRODUCCIÓN}

Cuando comenzamos esta investigación sobre la geografía lingüística del judeoespañol según el léxico, nuestro propósito era configurar un mapa geográfico-lingüístico en el que habrían de quedar definidos los diferentes grupos dialectales del judeoespañol hablado en comunidades sefardies de Turquía, los Países Balcánicos e Israel de manera similar a como aparece en nuestro estudio exclusivamente fonológico "Variación diatópica del Judeoespañol en los Países de los Balcanes y en Turquía" ". Las variedades dialectales de las comunidades sefardies analizadas entonces, quedaron agrupadas en tres grupos claramente definidos: el "noroccidental" (comunidades de Sarajevo, Belgrado, Monastir y Castoría); el "suroriental" (Estambul, Bursa y Esmirna en Turquía; Burgas y Varna al este de Bulgaria, Dúpnica y Pazardjik en el sur de Bulgaria, además de Salónica, Verria y Skopje) y, por último, el "nororiental" (comunidades del resto de Bulgaria, y de Rumania) que realmente es un grupo puente entre los otros dos, puesto que algunos de los isofonos transcurren por diferentes lugares. Pero en el desarrollo de la presente investigación, poco a poco, se fue demostrando que

* Con esta investigación qujero rendir homenaje al desaparecido profesor Israel Salvatore Révah, ahora que está a punto de cumplirse el treinta aniversario de su fallecimiento (1973) y expresar mi más considerable agradecimiento a sus descendientes, en especial a Jean-François Révah, por haber puesto a mi disposición los valiosos materiales con los que cuenta el archivo personal de su padre, algunos de los cuales sirvieron de fuente en este trabajo. Mi agradecimiento también al profesor David. M. Bunis por sus importantes sugerencias.

'Aldina Quintana, «Diatopische Variation des Judenspanischen in den Balkanländern und in der Türkei», Neue Romania, 19, 1997, págs. 47-65.

RFE, LXXXII, 2002, 1. $.^{\circ}-2 .^{\circ}$, págs. 105-138 
una conclusión con resultados similares se planteaba más que problemática, pero no por ello menos interesante.

\section{CORPUS}

El corpus de la presente investigación mantiene abundantes similitudes con el empleado en el mencionado estudio fonológico, especialmente por tratarse, en su mayor parte, de material lingüístico registrado en las primeras cuatro décadas del siglo xx. Respecto a los materiales cotejados, en su mayoria diccionarios e investigaciones descriptivas de las diferentes variedades sefardíes, cabe señalar que entonces no habiamos incluido los diccionarios de Mošé ${ }^{2}$ y Révah ${ }^{3}$ sobre la lengua de la comunidad de Salónica, de Cherezli ${ }^{4}$ sobre la lengua de Jerusalén, de Pardo ${ }^{5}$ para la de Esmirna, de Pipano ${ }^{6}$ para la de Sofia, de Maimon ${ }^{7}$ para la lengua sefardí de Bursa, de Perahya ${ }^{8}$ para la de Estambul y de Romano ${ }^{9}$ para el judeoespañol de Sarajevo. También disponemos ahora de material proporcionado por algunos informantes, además de las valiosisimas notas pertenecientes al archivo del profesor Israel Salvatore Révah que él mismo obtuvo a través de cuatro entrevistas realizadas en París en los años sesenta con hablantes sefardíes, las cuales nos proporcionaron informaciones sobre formas léxicas de Vidín, Bucarest, Estambul y Esmirna.

\section{Formas SELECCIONADAS Y CRITERJOS DE SELECCIÓN}

La elección de las formas léxicas seleccionadas responde a los siguientes criterios:

\footnotetext{
${ }^{2}$ Menahem Mošé, Milon Kis yehudi-sefardí - ibri, Salónica, 1934.

${ }^{3}$ Israel Salvatore Révah, ms. "Dictionnaire du Judéo-Espagnol", Letras A-M [París, s.a. (a. 1970)].

${ }^{4}$ Salomon Israel Cherezli, Ciko diksyonaryo žudeo-espanyol-franses, 2 vols., Jerusalén, 1899.

${ }^{5} \mathrm{~N}$. de Y. Pardo, Milon ladino-ivri - šarfati [Esmirna, a, de 1900], ms. 3581 del Instituto Ben Zvi de Jerusalén.

${ }^{6}$ Albert D. Pipano, Diksyonaryo Žudeo-espanyol - bulgaro. Sofia, 1913.

${ }^{7}$ Sam Maimon, "Ladino-English Dictionary», Studies in Sephardic Culture. The David N. Barocas Memorial Volume, editado por Marc D. Angel, Nueva York, Sepher-Hermon Press, 1980 , págs. 109-178.

${ }^{\text {B }}$ Klara Perahya e.a., hudeo-Espanyol - Türkçe. Türkçe - Judeo-Espanyol, Estambul, Gözlem, 1997 y Klara Perahya y Elie Perahya, Dictionnaire Français - Judéo-espagnol, Paris, Langues \& Mondes, 1998.

${ }^{2}$ Samuel Romano, Dictionary of Spoken Judeo-Spanish/French/German. With an Introduction on Phonetics and Word Formation. A photocopy of the original manuscript (Ph.d Thesis submitted to the University of Zagreb, 1933) with a foreword by David M. Bunis, Jerusalén, Misgav Yerushalayim, 1995.
} 


\subsection{Criterios lexicológicos}

3.1.1. Lexemas que presentan variación formal en el sistema léxico sefardí de Salónica y de Estambul, comunidades que hasta el siglo xvili fueron los principales centros culturales del sefardismo en el Imperio Otomano, debido a la coexistencia de normas diferentes (SALÓNICA: /fēožénto, fégado, doýe, mursjégano, bézba, bostežár, kwidádo, -gartiža/; ESTAMBUL: /fur(r)užénto, (l)ígado, dóze, mursjegáno, bízba, bostezár, kudjádo, lagartéža/).

3.1.2. Significantes diferentes según la comunidad, para un mismo signifícado (SALÓNICA: /lónŷe, sanbašúga, ŷinŷíbres, mangrána, kóda/; ESTAMBUL: /léšos, sanŷir(g)wéla, (z)inzías, granáda, kóla/).

\subsection{Criterios históricos}

3.2.1. Formas documentadas en el área castellana de la Península Ibérica, consideradas arcaicas o de uso popular (/fur(r)užénto, fégado, dóże y tréże, mursjégo/) por haber sido sustituidas ya a finales del siglo xV por otras más modernas o de más prestigio (/fēožénto, (f)igado, dóze y tréże, mursjélago/), al menos en la norma literaria.

3.2.2. Formas documentadas antes de 1492 en lenguas de la Peninsula Ibérica, no presentes en el castellano de la misma época. Entre ellas, las

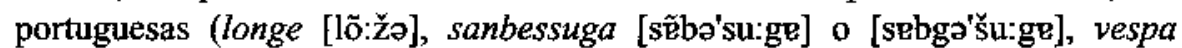
[véspa], gengivas [Žě'ží:ves], bocejar [busə'ža:r]); las catalano-aragonesas (magrana [mə(g)gránə], sucre [súkrə]); las aragonesas (coda [kóda], cudiado [kudjádo], lagartija [lagartiža]) que se corresponden con las respectivas formas castellanas (/léšos, sangwéla vs. sangiŷwéla, abíspa, ensías, granáda, asúkar, kóla, kwidádo, lagartíša/), esta última desconocida en judeoespañol.

\section{El CASTEllano Y EL JUDEOESPAÑol EN RELACIón}

Antes de comenzar con el análisis propuesto, es preciso hacer una aclaración respecto al término "castellano" que aparecerá con frecuencia en este estudio. Cuando ponemos en relación al judeoespañol con el "castellano", debemos especificar de qué castellano estamos hablando. Sin duda, se trata del "castellano medieval" 10 , y más concretamente del castellano del siglo $\mathrm{xv}$

\footnotetext{
${ }^{10}$ Cfr. Rafael Cano Aguilar, El español a través de los tiempos, Madrid, Arco/Libros,
} 1988 , págs. 67-220, para más detåles. 
que, por ser una lengua en constante expansión hasta 1492, presentaba bastante variación diatópica y un elevado polimorfismo, menos evidente en la lengua literaria que en la lengua hablada, lo cual explica que formas léxicas y voces del sistema léxico sefardí de ese origen no se encuentren apenas documentadas o ni siquiera haya quedado constancia de ellas en textos de la Península Ibérica. A este respecto se puede, al menos, suponer que entre las formas no documentadas también hubo alguna de uso limitado a la lengua oral de los judíos de Sefarad.

Además, en el siglo $\mathrm{xv}$ la lengua literaria castellana presentó varias novedades. Entre ellas destaca "la interrupción de una nueva sensibilidad "humanista', vuelta hacia el mundo clásico, en especial el latino..., pero inspirada directamente por la literatura italiana a partir de Dante" "1", porque entonces no afectó prácticamente a la lengua hablada por el vulgo, por lo tanto la lengua de los judíos españoles que conformarían más tarde las comunidades sefardíes orientales se vio libre de las repercusiones de los cultismos, excepto en autores como Moše ben Baruh Almosnino ${ }^{12}$ y Daniel de Ávila Gallego ${ }^{13}$, constituyendo este aspecto uno de los que con más evidencia separa la lengua de los sefardíes otomanos de las lenguas de la Península Ibérica y de Iberoamérica a todos los niveles. El término "castellano medieval" no tiene tampoco un significado limitado a la norma toledana empleada en 1492, sino que también puede hacer referencia a otras normas castellanas que entonces coexistian con aquella.

La lengua de los sefardíes tampoco se vio afectada por los cambios lingüísticos que tuvieron lugar en el castellano de los siglos xVI y xVII, que en muchos casos supusieron la culminación de cambios en marcha de épocas anteriores y que, por lo tanto, también en judeoespañol siguieron su propio desarrollo con independencia de lo que estaba aconteciendo en el castellano de la Península Ibérica.

\section{ANÁLISIS DE LAS FORMAS LÉXICAS}

Para poder seguir este capitulo, remito al lector a la tabla que contiene la distribución geográfica de las diferentes formas de cada uno de los lexemas aquí analizados, según su uso en el habla de las comunidades sefardies tenidas en cuenta (sus nombres aparecen en la columna de la izquierda).

\footnotetext{
${ }^{11} \mathrm{Cfr}$. Aguilar, El español a través de los tiempos, pág. 203.

12 P. ej. en la obra, Livro entitulado reŷimyento dela vida, Salónica, 1564, se observa el uso de ciertos cultismos italianos.

${ }^{13}$ En su obra, Dyalogo del Kolorado, Salónica, 1601.
} 
En la parte superior de la tabla se pueden consultar las formas castellanas de la época de la expulsión que se corresponden con cada uno de los lexemas analizados, algunas de las cuales constituyen la base etimológica de las correspondientes formas sefardíes, como se puede observar siguiendo las columnas en la dirección de arriba hacia abajo.

En la parte inferior de la tabla se pueden consultar las formas consideradas arcaicas con relación a la norma dominante del castellano literario de 1492, bien por haberse producido cambios fonéticos o fonológicos en dicha lengua o bien por haber sido sustituidas por otras (columnas 1-4). Otro grupo lo constituyen los lexemas no castellanos, pero que son o fueron parte integral de sistema léxico de otras lenguas habladas en la Península Ibérica: gallego-portugués (columnas 5-9), catalán o aragonés (columnas 10-14). De igual modo, para comprobar las formas presentes en la lengua de las comunidades sefardíes que tienen a las no castellanas como base, se recomienda seguir la tabla de abajo hacia arriba.

En este capítulo en el que trataremos de las formas léxicas sefardíes, seguimos el orden de la tabla de izquierda a derecha. Por ser este un trabajo lexicológico, prescindiremos, en la medida de lo posible, de explicaciones de carácter fonológico. No renunciamos, sin embargo, a escribir las formas analizadas con la correspondiente escritura fonológica (entre barras /žẽnžívas/), fonética (entre corchetes [žẽěžives]) o en algunos casos grafética (entre paréntesis angulares $<$ gengivas $>$ ).

\section{1. /ferožénto - furužěnto/}

Lat. vg. FERRŨGO, -GĨNIS. Este lexema fue sustituido en castellano por la forma culta oxidado, sin embargo, la base léxica se conserva en la forma dialectal del noroeste de la Península, ferruje.

La forma /ferožénto/ se corresponde con la castellana antigua, mientras que [furužéntu] es una forma del habla popular de zonas aisladas y se usa todavía en Galicia y en Asturias.

Esta es una de las pocas palabras que conserva la $f$ - inicial en todas las variedades del judeoespañol y también en la haquitía de Marruecos, donde se dice $/$ ferožénto/ ${ }^{14}$. La distribución de una $\mathbf{u}$ otra variante en judeoespañol remite, sin duda, al período en el que tuvo lugar el primer proceso de nivelación lingüística entre diferentes normas en las primeras comunidades sefardíes creadas después de la expulsión. Esta es la manera más lógica de explicar la presencia de la forma con $-u$-, la de menos prestigio, en comu-

${ }^{14}$ José Benoliel, Dialecto Judeo-Hispano-Marroquí o Hakitia, Madrid, 1977, pág. 198. 


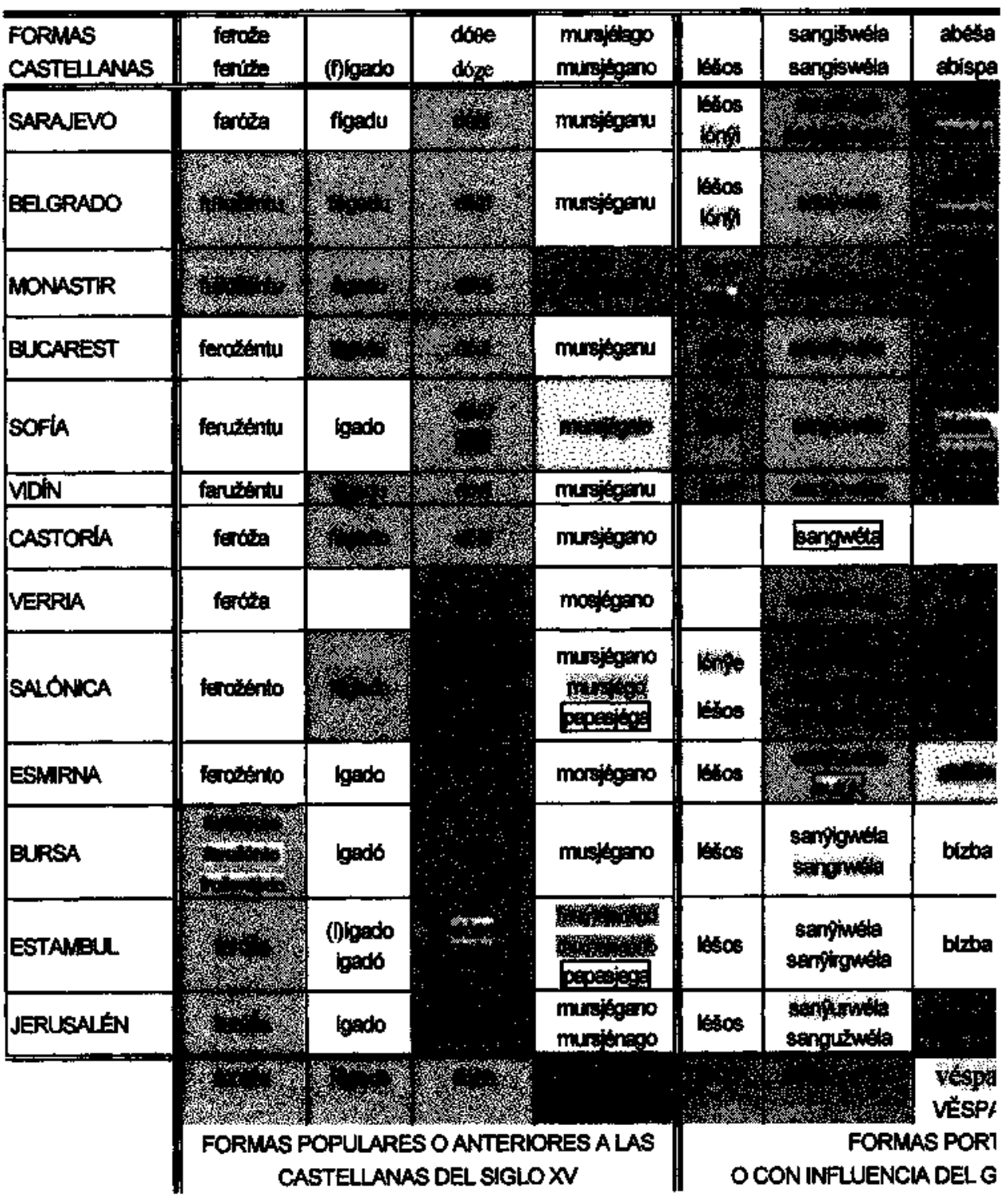

Distribución diatópica de catorce formas léxic 


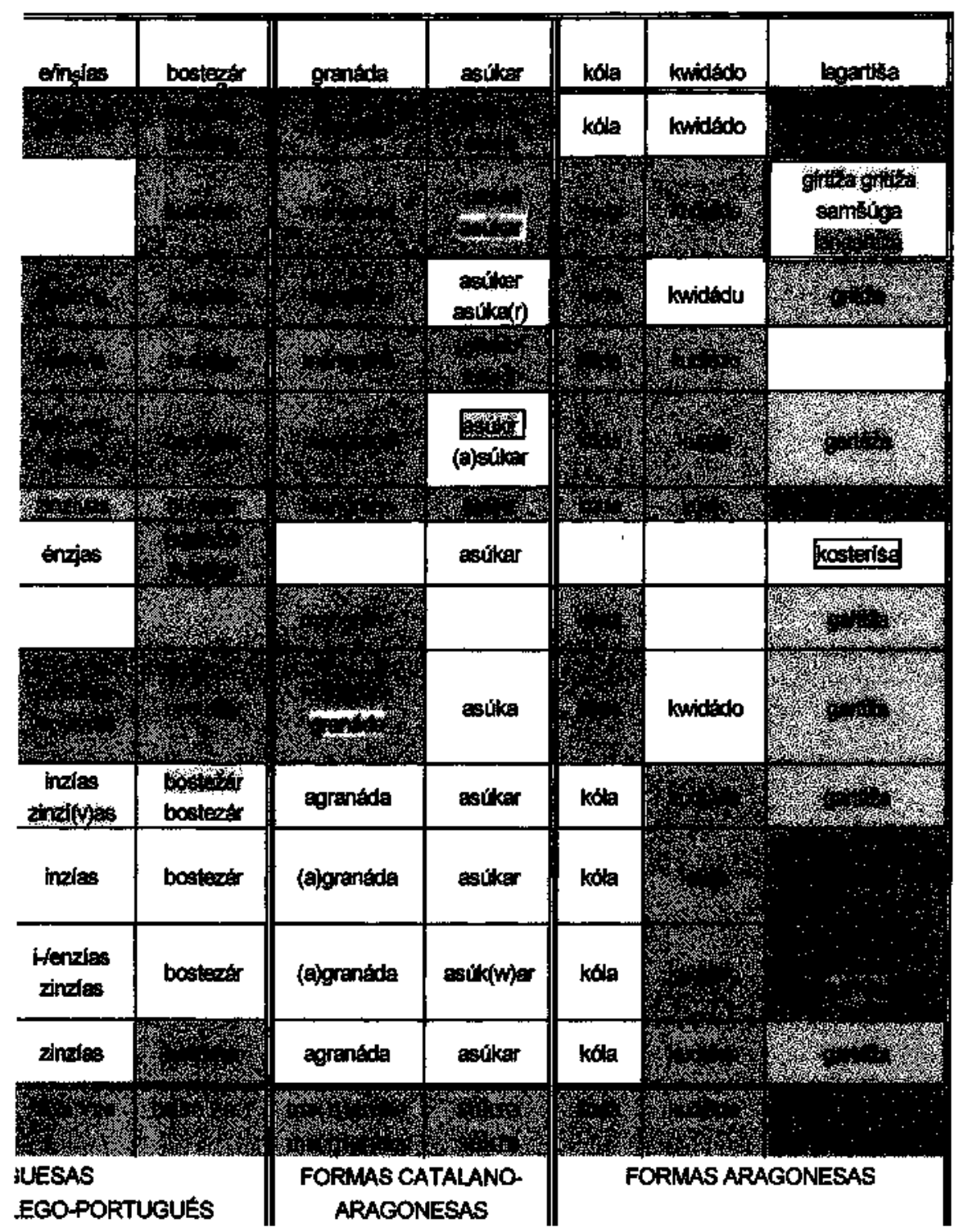

, lexemas del judeoespañol otomano. 
nidades tan distantes y con una identidad propia como la de Estambul y la de Monastir, esta última bastante aislada y que mantenia lógicamente contactos más estrechos con Salónica donde pervivió la forma con $-e$-. Precisamente de Salónica se debe de haber llevado la forma con $-e$ - a otras comunidades, como a la de Esmirna, situada en la zona de influencia de Estambul que, sin embargo, ofrece la particularidad de contener en su léxico algunas otras formas (/gartéža, morsjégano/), con mucha probabilidad, introducidas igualmente a través de la influencia ejercida allí a finales del siglo XVI por los sefardies procedentes de Salónica. La forma de Bursa es también /furožénto/; una segunda forma, sincopada en este caso, /frožentádo/ nos fue proporcionada por un informante de Israel, cuya familia por parte paterna procedía de Bursa. Esta forma presupone la existencia anterior de /ferožénto/, forma que también fue facilitada por el mismo informante. Tampoco esta última forma era desconocida en Estambul, pues es la recogida en el diccionario de Perahya ${ }^{15}$, lo cual nos lleva a concluir que la presencia de ambas formas en las comunidades de Estambul y Bursa responde, sin duda, a una función de variantes estilísticas: /fēožénto/ es la forma con más prestigio, mientras que /furužénto/ se usa en situaciones de comunicación más informal. Todo parece indicar que nos encontramos aquí con dos variantes léxicas, procedentes de dialectos diferentes, que en el nuevo dialecto adquirieron la función de variantes alofónicas con función estilística.

Por su parte, en la variedad de Jerusalén encontramos solamente la forma /furuža/ y /furužénto/, lo cual apunta hacia la definitiva predilección por la forma de origen no castellano. La difinitiva elección de esta forma por parte de los hablantes de esta comunidad debe haber tenido lugar en un período tardio, puesto que a Jerusalén llegaban con frecuencia sefardies de otras comunidades, no sólo de las situadas en la actual Turquía, y especialmente de Salónica, que traerían consigo la forma /ferožénto/.

\section{2. /(f)égado - (figado/}

Lat. vg. FícATUM, aunque también FÉcATUM se encuentra documentada ${ }^{16}$. El castellano actual cuenta con la forma <hígado>/ígado/. En 1492 en Castilla la Vieja se había iniciado ya el proceso de pérdida de la $f$-inicial latina, lo cual explica que esta variante fuera llevada también por los sefar-

\footnotetext{
${ }^{15}$ Perahya e.a., Judeo-Espanyol - Türkçe. Türkçe - Judeo-Espanyol, pág. 106.

16 J. Corominas y J. A. Pascual, Diccionario crítico etimológico castellano e hispánico, vol. III, Madrid, Gredos, 1980, págs. 357-358.
} 
dies a las comunidades del Imperio Otomano. Las lenguas y dialectos no castellanos, conservaban la $f$.

De las diferentes variantes existentes en la Península Ibérica proceden todas las formas documentadas en las comunidades del Imperio Otomano, así como /figado/ ${ }^{17}$, la forma presente en haquitía. Esta última era precisamente la forma más frecuente en la Península Ibérica antes de 1492. Sin embargo, en Asturias, León, incluso en Extremadura y en Galicia, se usaba y se continúa usando /fégadu/. Por su parte, en el léxico portugués también triunfó la forma con $-i-$, como en castellano. Entre los sefardies /fégado/ era una variante minoritaria.

Las variantes de este lexema ofrecen una distribución diatópica muy interesante en las variedades sefardíes, debido a que la forma con $-i-/(f) i g a d o /$, propia de Estambul, empleada en las comunidades de Bursa, Esmirna y Jerusalén, la encontramos también en Sofia y en Sarajevo, comunidades situadas dentro del área de dominio de /fégado/. Debemos destacar, además, que los sefardíes de Bucarest emplearan la forma /égadu/, lo cual puede resultar una paradoja, dado que fueron precisamente judios de Estambul los que a finales del siglo XvIII fundaron la comunidad sefardi ${ }^{18}$, aunque ya en el siglo Xvı hubiera algunos sefardíes allí ${ }^{19}$. La presencia de /égadu/ en la comunidad rumana parece más bien ocasionada por la influencia lingüistica ejercida desde las comunidades vecinas, como Vidín y Ruse, en las que aparece /égadu/; esta influencia es apreciable también en la pronunciación de las vocales finales $-\mathrm{y}-\mathrm{y}$ como cerradas. La comunidad sefardi de Vidín se creó en el siglo XVI, sus miembros procedían de Salónica ${ }^{20}$. Además, esta comunidad se encontraba en una de las rutas comerciales (Salónica-Sofia-Vidín) con el interior de los Balcanes ${ }^{21}$. Vidín parece haber sido también un centro de estudio del judaísmo sefardi después del siglo XVIII, puesto que durante bastante tiempo los rabinos de Ruse y Bucarest procedían de aquella ciudad ${ }^{22}$. En Ruse, comunidad fundada a finales del siglo xviII por sefardies procedentes de Belgrado, Nish, Edirne (Adrianópolis) ${ }^{23}$ y Vidinn ${ }^{24}$, se impuso también la forma con $-e$.

\footnotetext{
${ }^{17}$ Benoliel, Dialecto..., pág. 199.

${ }^{18}$ Encyclopedia Judaica, Jerusalén, Keter Publishing House, 1971, bajo "Bucharest".

${ }^{19}$ Id. Sin embargo, no parece haber existido una comunidad sefardí en el siglo XVr en Bucarest, sino solamente algunas familias, segun se desprende de los Responsa del rabino Samuel de Medina, Š uđ Maharašdam, vol. 2, Salónica, 1594, Responsum núm. 5.

${ }^{20}$ Encyclopedia Judaica, 1971, bajo "Vidin".

${ }^{21}$ E. Benbassa y A. Rodrigue, Juifs des Balkans, París, Editions la Découverte, 1993, pág. 112 .

22 Selomo Rozanes, Estorya de la komunidad israelita de Rus'ĉuk, Ruse, 1914, págs. 21-22.

${ }^{23}$ Rozanes, pág. 16.

24 Rozanes, pág. 20.
} 
La variante/figadu/ de Sarajevo, comunidad creada por sefardies procedentes de Salónica, nos confirma que en esta última comunidad existió también la forma /figado/ en la lengua hablada hasta que la forma con -é- la sustituyó, hecho que se confirma en la lengua escrita de Salónica del siglo XVI, donde se empleaba la forma con $-i-{ }^{25}$. En Sarajevo se continuó empleando la forma con $-\mathrm{i}-$, por ser considerada en aquel entonces ya como la más culta. La existencia en el pasado de una forma con -é- en Sarajevo es poco probable. En los textos en caligrafía latina ${ }^{26}$ del siglo $\mathrm{xx}$ siempre aparece $<$ figado>, y lo mismo confirman nuestros informantes. Para terminar, digamos que la forma con $-e ́$ - de Salónica, se extendió desde esta comunidad a otras en el interior de los Balcanes con las que la metrópoli macedónica mantenía relaciones muy estrechas hasta finales del siglo XIX.

El triunfo de una u otra pronunciación en cada comunidad responde a la elección de los hablantes. Lo más adecuado es suponer que en las dos grandes comunidades sefardies, Salónica y Estambul, coexistieron ambas pronunciaciones, dependiendo una $\mathrm{u}$ otra del origen de los hablantes. Solamente el resultado final al que condujo el proceso de nivelación fue diferente en cada una de ellas. La presencia actual de una $\mathbf{u}$ otra forma es el resultado de una elección entre formas y no responde a ningún cambio fonológico general, pues las vocales tónicas no se han visto sometidas a cambios en ninguna de las variedades sefardíes.

La forma registrada en Estambul /ligadó $/{ }^{27}$ proviene de la fusión de la consonante final del artículo masculino el con la vocal inicial del sustantivo, fenómeno que también encontramos en lonso (sic, oso), incluso en librik (sic, cafetera $)^{28}$, lexema formado a partir del turco <ibrik> .

\section{3. /dóze tréże - dóze, tréze - dóye, treŷe/}

Las tres formas sefardíes de este lexema representan otros tantos estados de su evolución fonológica y no responden a grafías vacilantes. De ellas,

${ }^{25}$ Séfer Sulhán Hapanim yamado en ladino Meza del Alma, Salónica, 1568, pág. 3, 93v, $96 \mathrm{v}$ como <figado> y $94 \mathrm{v}$ como <higado>.

${ }^{26}$ Aunque resulte redundante, nos parece necesario recordar que los sefardies usaron la caligrafia hebrea, tanto en manuscritos como en textos impresos hasta entrado el siglo xx. Dado que en la mayoría de estos textos se emplea un único grafema, la letra yod hebrea, para representar los fonemas vocálicos $/ \mathrm{e} / \mathrm{e} / \mathrm{j} /$, comprobar la distinción de pronunciación entre uno y otro se hace imposible, excepto en aquellos que aparecen con vocalización plena, como el mencionado en la nota anterior. De igual manera, los textos escritos en caligrafia latina, permiten observar dicho extremo.

${ }^{27}$ Max Leopold Wagner, Beiträge zur Kenntnis des Judenspanischen von Konstantinopel, Viena, Kaiserliche Akademie der Wissenschaften, 1914, pág. 144.

${ }^{28}$ Cfr. Perahya, Dictionnaire Français - Judéo-espagnol, bajo "cafetière", pág. 89. 
las formas con $/ \hat{z} /$ representan el estado más arcaico. De manera excepcional, algunas variedades sefardíes (Sarajevo, Belgrado, Viena, Monastir, Pristina, Dubrovnik, Castoría, Bucarest, Craiova, Vidín, Sofia, Dúpnica, Ruse) conservaron la africada dental en un número muy limitado de palabras: /doẑe, treẑe, poẑo/, mientras que en el resto de las variedades la desafricación del fonema dental sonoro alcanzó a todo el sistema léxico ${ }^{29}$. En algunas comunidades (Estambul, Edime, Esmirna, Bursa, Galipolis, Skopje, Sofia, Plovdiv, Pleven, Ruse, Castoría, Salónica, Verria, Rodas, Quíos, El Cairo y Jerusalén), las voces en cuestión tuvieron una evolución diferente según la cual la sibilante conservó la africación, pero cambió de punto de articulación, pasando a pronunciarse como palatal. El cambio de $[\hat{z}]$ a $[\hat{y}]$, en los numerales doce y trece estaba consolidado en la mayoría de estas comunidades ya en el siglo $\mathrm{xvIII}^{30}$. En textos de Salónica de aquel tiempo y en textos de Esmirna del siglo $\mathrm{XIX}^{31}$, las formas con $/ \hat{\mathrm{y}} /$ son generales lo mismo que en Castoría, Verria, Skopje y Plovdiv. En Ruse y Estambul se da también [dóze, tréze, pózo] como variantes de [dóye, tréŷe, póyo]. El fonema prepalatal fricativo sonoro $/ \hat{z} /$ tiene en judeoespañol una realización africada palatal $[\hat{y}-]$ en posición inicial de palabra y precedido de nasal o líquida, mientras que entre vocales y precedido por otra consonante se pronuncia como fricativo. Sin embargo, los lexemas mencionados antes se pronuncian con $[\hat{y}]$, aun cuando este aparece en posición intervocálica.

En Estambul estos lexemas se pronunciaron con $[z]^{32}$ y en parte, se continúan pronunciando, puesto que no todos los hablantes sefardíes de esta comunidad emplean /dóye, tréye ${ }^{33}$. La introducción de la última pronunciación parece remitir a las últimas generaciones, probablemente bajo la influencia de las otras comunidades.

En Sofía junto a la forma con africada dental /dóẑe, tréẑe/, propia de las variedades del interior, también es conocida la variante con africada palatal /dóye/, la única que se usa en Salónica.

29 Aldina Quintana, «Dialektologie des Judenspanischen», Tesis de Licenciatura, abril 1991, Univ. Libre de Berlín, pág. 56.

${ }^{30}$ Révah, «Formation et évolution des parlers judéo-espagnols des Balkans», Actas du Xe Congrès International de Linguistique et Philologie Romanes, vol. III, editado por Georges Straka, Paris, Klincksieck, 1965, pág. 1365.

31 Reuben Ben Abraham d'Iștip, Tikuné Hanéfeš, Salónica, 1765, págs. 1 y 81 para las formas de Salónica; Eliahu Hacohen, Séfer Š́vet Musár, Ermirna, 1860, págs. 77v y 78, Yaakov Julí, Séfer Me'am Lo'ez. Berešid, Esmirna, 1864, págs. 5 y $280 \mathrm{v}$, y por último (s.a.), Pirké Rébi Elyezer, Esmirna, 1876, pág. 22 para las formas de Esmirna.

32 Para los cardinales "12" y "13" se pueden consultar las diferentes ediciones del Séfer Me'am Lo'ez. En su primera edición de Bereši $₫$. Constantinopla 1730, se encuentran ejemplos en la pág. 3v en la que empieza la introducción en "ladino", así como también en la pág. 8r.

${ }^{33}$ No solamente hemos recogido esta pronunciación de hablantes, sino que es la única que ofrecen Perahya e.a., Judeo-Espanyol - Türkçe. Türkçe - Judeo-Espanyol. 


\subsection{Imursjégo - mursjégano - musjegánol}

Lat. MUS o MUR (< gr. $\mu \nu \varsigma)$ caecus, 'ratón ciego'.

En castellano por composición de sustantivo y adjetivo se creó murciego $^{34}$, forma antigua que aparece en la General Estoria de Alfonso X (1275) y también es la que figura en la Biblia del Escorial I.J.8 [fol.3V] del año 1300 , y que todavía la encontramos en el judeoespañol de Salónica y Monastir. La forma fue ampliada en castellano a mursiégano, que es también la forma sefardi más frecuente ${ }^{35}$, a morsiégano, que encontramos en Esmirna y en Verria, y a mursiégalo, que derivó finalmente en el actual murciélago castellano y que en judeoespañol solamente encontramos en Sofia ${ }^{36}$.

Las formas /mursjégo/, /mursjégano/ y /musjégano/ son formas populares que aún hoy se oyen en España. Las tres variantes aparecen en textos medievales. La forma castellana moderna murciélago aparece ya como <murçielago> al lado de <murçiegano> en textos castellanos del siglo XiII.

En las traducciones ladinas del Pentateuco se da variación en el siglo Xvi: murçiegano y murçiegalo en el Pentateuco de Constantinopla y solamente morcielago en la Biblia de Ferrara, es decir, la forma castellana como era de esperar, mientras que en las traducciones posteriores aparece una única forma: morsiegano (Asa) y mursiegano (Ben Hayim) ${ }^{37}$. En la lengua de los sefardíes perduraron las formas más populares que fueron precisamente las que rechazó definitivamente la norma castellana en la Península Ibérica.

En Estambul, tanto si se pronuncia /musjegáno/ como /mursjegáno/, dicha voz sufrió un corrimiento del acento pasando a pronunciarse como llana. Probablemente se trate de una acentuación residual de origen aragonés, única variedad de la Península Ibérica en la que tiene lugar la conversión de palabras esdrujulas en llanas. Tampoco se debe descartar que el cambio

\footnotetext{
${ }^{34}$ En portugués antiguo existió la forma morsego, pero no parece haber sido ésta la base del mursiego sefardí.

35 "murciégano" aparece, por ejenplo, en el año 1561 en Luis Mílán, El cortesano, Madrid, Impr. de Aribau, 1874, pág. 211.

${ }^{36}$ Wagner, «Los dialectos judeoespañoles de Karaferia, Kastoria y Brusa», pág. 202.

37 Ladino Pentateuch, Estambul 1547, editado de nuevo por Moshe Lazar, California, Labyrinthos, 1988; Biblia de Ferrara, Ferrara, 1553; Hélek rišón mehaarbá veesrim vehú hamišá humš́ torá im laaz, traducida y editađa por A. b. Y. Asa, Constantinopla, 1739 y Séfer arbaá veesrim hélek rišón, traducida y editada por Israel Ben Hayim, Viena, 1813, en las porciones semanales Veyikrá (= Levítico) 11:19 y Devarím (= Deuterononio) 14:18 respectivamente. La forma de Séfer arbaá veesrim la damos de acuerdo con ta vocalización de Israel Ben Hayim 1923, pág. 170 .
} 
de acentuación se haya producido por analogía con la pronunciación de los adjetivos con sufijo $\{$-ano\}, como toledano, italiano, etc.

Además, en Salónica y Estambul actualmente se emplea también el lexema /papasjéga/ ${ }^{38}$ que es una formación sefardí. Sin embargo, Mošé ${ }^{39}$ traduce el lexema <papasjega> con la palabra hebrea que equivale a la castellana erizo.

\subsection{Réšos - lónŷe/}

Lat. LAXIUS > /lešos/ (cast.) y lat. siglo $\mathrm{X}$ LONGE > /lonŷe/ (port.)

En portugués se conservó la forma medieval, mientras que en castellano debido a un cambio fonológico general, la palatal šišeante de /lešos/ se velarizó, pasando a pronunciarse /léxos/.

La primera particularidad que presenta la distribución diatópica de estas dos voces en judeoespañol es que hay comunidades (señaladas en la tabla con /léšos/) en las que la forma /lónŷe/ es desconocida. Otras, como la de Salónica, poseen ambas formas, aunque la forma /lónŷe/ tiene un uso mucho más frecuente, mientras en Sarajevo y Belgrado /léšos/ es el lexema usual. La última generación de hablantes de judeoespañol de Sarajevo ya no conoce la forma /lónŷi/. En las comunidades de Turquía, /lónŷe/ se considera una forma desconocida, mientras que parece haber sido la única forma de Sofia ${ }^{40}$. La presencia de la forma castellana /léšos/ en los extremos geográficos del espacio sefardí, como también ocurre con /(f)ígado/ y /kóla/, parece indicar que la forma /lónŷe/ entró en la lengua sefardí más tarde. La presencia de /lónŷi/ en las comunidades del centro de los Balcanes, se explica a través de la expansión de la forma desde Salónica, adonde seria llevada por los anusim de Portugal después del siglo XVI. De hecho, /léšos/ es la única forma que aparece en los textos sefardies de siglo $\mathrm{XvI}^{41}$ escritos en Salónica y también en las traducciones ladinas de la Biblia ${ }^{42}$.

\footnotetext{
${ }^{38}$ Joseph Nehama, Dictionnaire du Judéo-Espagnol, Madrid, CSIC, 1977 y Perahya, Dictionnaire Français - Kudéo-espagnol.

${ }^{39}$ Mošé, Milon Kis yehudí-sefardi - ibri.

${ }^{40}$ Pipano, Diksyonaryo žıdeo-espanyol - bulgaro, pág. 60, incluye solamente esta variante. También una informante de Révah, originaria de Sofia da /lónye/ como única forma (mss. del archivo personal de Révah).

${ }^{41}$ Moše ben Baruh Almosnino, Crónica de los Reyes Otomanos, ms. a. 1568, editado por Pilar Romeu Ferré, Barcelona, Tirocinio, 1998, pág. 230.

${ }^{42}$ Cfr. Ladino Pentateuch, Estambul 1547; Biblia de Ferrara, Ferrara, 1553, Hélek rišón mehaarbá veesrim vehú hamišá humš́ torá im laaz, Constantinopla, 1739 y Séfer arbaá veesrim hélek riǒón. Viena, 1813, en las porciones semanales Berešiđ (= Génesis) 22:4 y 37:18; Šemóđ (= Exodo) $2: 4,20: 15,20: 18$ y 24:1 y Devarim (= Deuteronomio) $28: 49$.
} 


\section{6. /sanŷigwéla - sanŷwéla - šambašrúgal}

Lat. cl. SANGUISUGA

Lo mismo que en las lenguas y dialectos de la Península Ibérica, también en judeoespañol existe una rica gama de formas para denominar a un animal tan popular por su uso como fue la sanguijuela. Las formas usadas por los sefardíes las podemos agrupar de la siguiente manera:

a) Formas derivadas del antiguo gallego-portugués $<$ sambesuga $>43$ : /sanbešúga/ (Salónica) >

a'. /sambašúga/ (Salónica, Monastir) > /šambašúga/ (Salónica, Verria)

b'./samišúga/ (Sarajevo) >/šam(i)šúga/ (Sarajevo).

b) Formas castellanas:

1. Formas derivadas de la base léxica castellana sang(re) + suf. dim. - uela: a'. /sangwéla/ > /sanŷ̀wéla/ (Belgrado, Ruse, Bucarest) > /sanŷuwéla/ (Sofia, Vidín, Pazardjik, Esmirna).

b'. /sangrwéla/44 ${ }^{4}$ (Bursa) > /sanŷurwéla/ (Jerusalén).

El lexema /sanŷwéla/ se encuentra documentado en uno de los textos más próximos a la variante popular sefardí del siglo xvi: Séfer Héšeq Šelomó $(1588)^{45}$. Su presencia en el léxico judeoespañol confirma que también así fue llamado este pequeño animal, algo que Corominas y Pascual consideraban incomprensible ${ }^{46}$.

2. Formas derivadas de la base léxica de la forma vulgar *SANGU SUJOLA. $a^{2}$. /sangî̀wéla/ ${ }^{47}>/$ sanŷigwéla/ (Bursa) $>$ /sanŷirgwéla/ (Estambul) $>$

b'. /sangužwela/ ${ }^{48}$ (Jerusalén). /sanŷirwéla/ (Estambul, Edirne).

\footnotetext{
${ }^{43}$ Wagner, «Los dialectos judeoespañoles de Karaferia, Kastoria y Brusa», Homenaje ofrecido a Menéndez Pidal, vol. II, Madrid, 1925, pág. 197. Esta forma es totalmente desconocida fuera de la zona gallego-portuguesa, excepto en el dialecto leonés en el que existe la forma "samagusa", emparentada con sus formas vecinas.

${ }^{44}$ Una variante "sangrusuela" aparece en las glosas del Escorial, según Corominas y Pascual, Diccionario..., vol. V, 1983, pág. 152.

${ }^{45}$ David M. Bunis, «Tres formas de ladinar la Biblia en Italia en los siglos xvl-Xvi», Introducción a la Biblia de Ferrara, Actas del Simposio Internacional sobre la Bíblia de Ferrara, Sevilla, 25-28.11.1991, ed. por J. Hassán, Madrid, CSIC e.a., 1994, pág. 329.

46 Corominas y Pascual, Diccionario..., vol. V, 1983, pág. 152.

${ }^{47}$ Wagner, «Los dialectos judeoespañoles de Karaferia, Kastoria y Brusas», pág. 197.

48 Forma ya documentada antes de la expulsión, hacia 1300, en Cavallero Zifar, págs. 373 y 374 del ms. M. según Corominas y Pascual, Diccionario..., vol. V, 1983, pág. 152. Una variante de la misma era también sangusuela, documentada en Tratado de las Enfermedades de las Aves (fin del siglo Xult), íd.
} 
Estas dos formas proceden de la supuesta pronunciación vulgar *SANGU SUjola que evolucionaría a ${ }^{*}$ sanguisyuela ${ }^{49}$ y después a la /sangiŷwéla/ sefardí y a la /sangiswéla/ castellana en el primer caso, y a *sangusyuela y /sangužwéla/ de Jerusalén en el segundo. Se trata, por tanto, de formas arcaicas que los sefardíes llevaron de la Península Ibérica.

La forma /sanŷigwéla/, que precisamente se corresponde con las formas de Bursa, Estambul y Edirne, es la que fue usada en las traducciones ladinas de la Biblia de los siglos xvIII y XIX ${ }^{50}$, mientras que en la Biblia de Ferrara (1553) figura la variante castellana $<$ sanguisuela $>$ 51, lexema ya inexistente en el judeoespañol otomano igual que otra de sus variantes, la forma culta /sangizwéla/, que sí se hallaba en uno de los textos clásicos del siglo $\mathrm{XVI}$.

Las cuatro formas base (/sambesúga, sangwéla, sangiŷwéla, sangužwéla/) fueron llevadas de la Península Ibérica. Fue dentro de las propias comunidades sefardíes donde tuvieron lugar los cambios fonéticos que dieron lugar a algunas nuevas variantes documentadas. En algunas comunidades perduraron varias formas hasta nuestros días. La distribución diatópica de la forma más frecuente/sanğwéla/, en comunidades que no fueron creadas inmediatamente después de la expulsión de 1492, indica que dicha forma fue llevada allí desde las principales comunidades, Salónica o Estambul. Por las formas documentadas en esta segunda comunidad, lo más probable es que dicha forma fuera llevada allí, como a Esmirna, desde Salónica, donde la forma sería sustituida más tarde a través de /šambašuga/, la forma de origen portugués (véase el mapa) y llevada a otras comunidades en estrecho contacto con Salónica. Por otra parte, en libros sefardíes de medicina popular editados en Esmirna a finales del siglo $\mathrm{xIX}^{53}$, se puede encontrar la palabra /sulúk/ procedente de la voz turca <sülük> o /sy:ly:k/, probable-

49 Como Corominas y Pascual, Diccionario... vol. V, 1983, pág. 152, suponen acertadamente.

${ }^{50} \mathrm{Cfr}$. Helek rišón mehaarbá veesrim vehú hamiša humšé torá im laaz, Constantinopla, 1739 y Séfer arbaá veesrim hélek revii, traducido y editado por Israel Ben Hayim, Viena, 1816, Mislé (= Proverbios) 30:15.

'Bunis, "Tres formas de ladinar la Biblia...», pág. 329. La forma sanguisuela existia en el año 1148 , según Corominas y Pascual, Diccionario..., vol. V, 1983, pág. 152.

52 Cfr. Séfer Šulhán Hapanim yamado en ladino Meza del Alma. Salónica, 1568, pág. $152 \mathrm{v}$.

${ }_{53}$ Este es el caso del Sefer Refuođ, Esmirna 5625 (1865), págs. 3, 6v. Esta edición se basa en otra anterior del mismo título, puede ser que editada en Salónica alrededor de 1850 , en la que en la mayoría de los casos podemos leer <sanbešugas> (pág. 3v, 7v) o <sanbašugas> (pág. 7v) en lugar de <sulúkes>. Todo parece indicar que la pajabra gallego-portuguesa fue sustituida deliberadamente por la turca por ser aquélla desconocida entre los sefardies de Esmirna. 
mente sustituyendo en gran medida, a la forma de origen castellano /sanŷwéla/ ${ }^{54}$.

La forma /sangwéta/ de Castoría y Dubrovnik es de origen veneciano ${ }^{55}$.

\section{7. bézba - bizba - bizbón - abižón/}

Lat. VĚSPA

/bizba/ y /bézba/ son un caso representativo de formas interdialectales surgidas a partir de las formas abeja y vespa o viespa. Por una parte, la forma con $-i$ - tónica procede de la reducción del diptongo de la forma heredada castellana viespa o aviespa ${ }^{56}$. Dicha reducción tuvo lugar debido a la influencia de la palabra abeja y como consecuencia de ello pasó a avispa en castellano. En el ámbito sefardí no se debe descartar la influencia del portugués vespa.

Deducimos un origen castellano para la forma /bízba/ de Estambul, Bursa y Sofia debido a la reducción del diptongo, mientras que /bézba/, documentada en el resto de las comunidades sefardíes procedería de la base léxica portuguesa que conservó la /e/ original latina sin diptongar. Además, la forma avespa es conocida en el portugués popular. La sonorización de [p], por asimilación de ésta a la [b-] inicial, puede haber tenido lugar después de la llegada de los sefardíes al Imperio Otomano y de hecho, así debe de haber sucedido a juzgar por las referencias con las que contamos.

Una peculiaridad especial en el espacio sefardí la constituye la presencia de /abižón/ en Esmirna que significa tanto 'abeja' como 'avispa" 57 , producto de una simplificación ocurrida entre /abeža/ y /abižon/, puesto que la primera la encontramos todavía en un texto sefardí de Esmirna de $1864^{58}$, pero no figura ya en el diccionario de Pardo, algo anterior a 1900, tampoco la cita la informante de Révah ${ }^{59}$ y en la actualidad es palabra desconocida entre los hablantes de judeoespañol de dicha comunidad que tuvimos la oportunidad de consultar.

\footnotetext{
${ }^{54}$ Esta última forma procede de las respuestas de un cuestionario reajizado por I.S. Révah a una informante de Esmirna (llamada Ester Arditi, nacida Asson, en 1875) y se encuentra en el archivo personal del desaparecido investigador.

${ }^{55}$ Wagner, «Los dialectos judeoespañoles de Karaferia, Kastoria y Brusa», pág. 201.

${ }^{56}$ Paul M. Lloyd, Del latin al español, I. Fonología y morfología históricas de la lengua española, Madrid, Gredos, 1993, pág. 505.

${ }^{57}$ Según Pardo, Milon ladino-ivri - Šarfati [Esmirna, a. de 1900\}, pág. 16, /abižón/ signifjca 'avispa'. Sin embargo, según las informaciones recogidas por Révah, mss. de su archivo personal, de una informante liamada Ester Arditi, nac. en 1875 en Esmína, el término vale tanto para 'abeja' como para 'avispa'.

${ }^{58}$ Séfer Zévah Pésah. Esmirna, 1864, pág. 2v.

${ }^{59}$ La informante mencionada con anterioridad solamente conoce /abjžón/ tanto para designar la 'avispa' como la 'abeja'.
} 


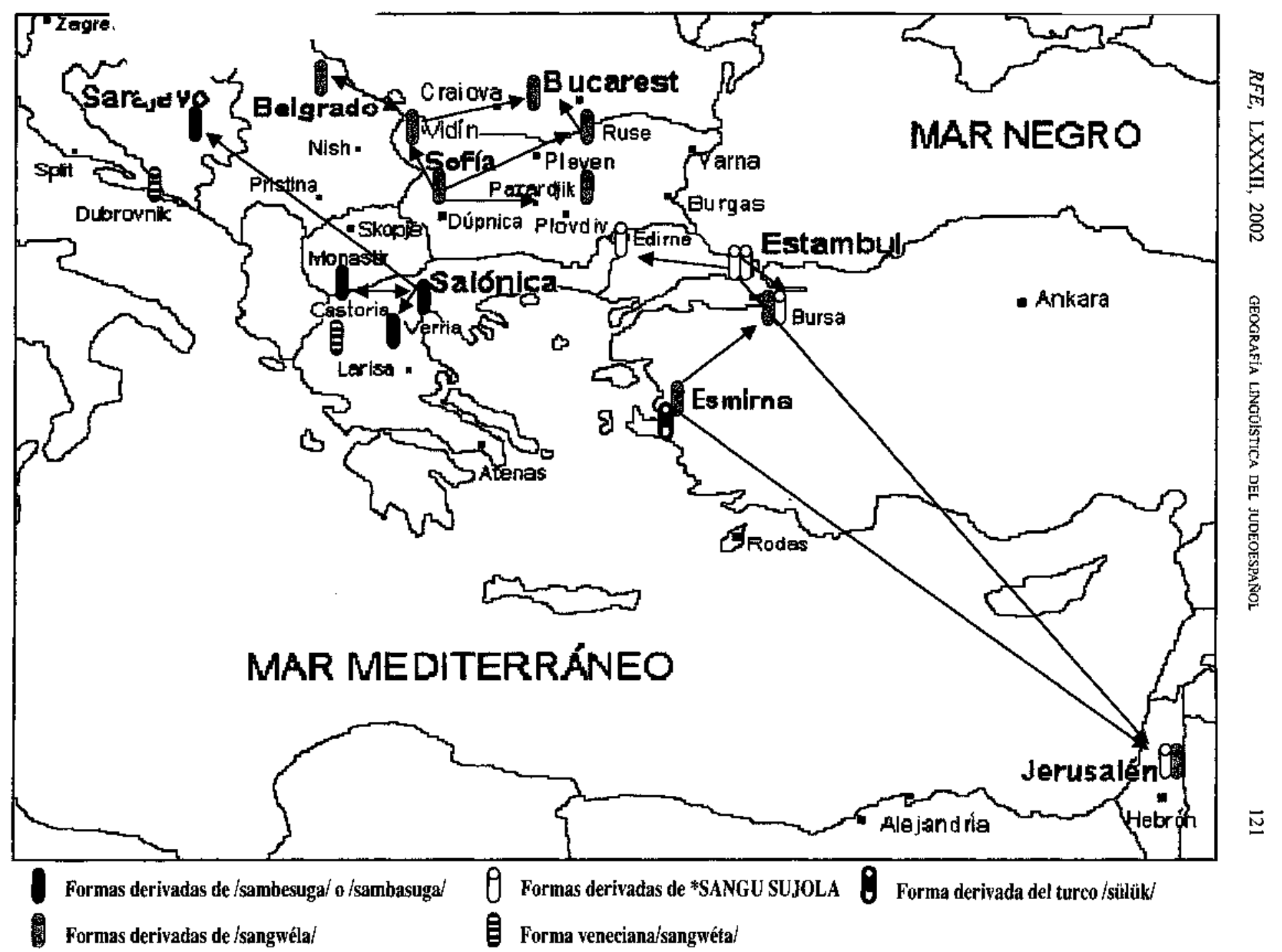


Otro aspecto interesante lo constituyen los cambios semánticos a que dichas formas se vieron sometidas. Si en la Península Ibérica todas las formas procedentes del étimo latino VĚsPA significan 'avispa', en el judeoespañol del siglo $\mathrm{xx}$ este significante tiene el significado de 'abeja'. En algunas comunidades sefardies parece no darse ningún tipo de distinción entre las abejas y las avispas. En otras, como Salónica, Verria, Sofia, Sarajevo y Belgrado se conserva la diferencia entre 'abeja', es decir, /bézba/ o /bízba/, y 'avispa', es decir, /bezbón/ o /bizbón/, diferencia paralela a la que existió en Esmirna y Estambul entre /abéža/ y /abížón/ y entre /abizba/: /abizbón/ respectivamente.

Mientras que en las traducciones ladinas de la Biblia realizadas en el si-

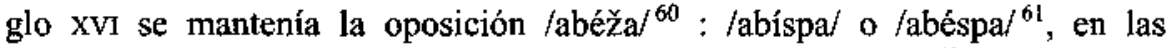
traducciones del siglo XvIII encontramos solamente $/ a b e ́ z b a /{ }^{62}$ y en las del siglo XIX encontramos /abézba/ o /abízba/ ${ }^{63}$ para traducir sendas palabras hebreas. Sin embargo, debemos de tener en cuenta que ya en 1588, Moisés Cordovero traducía el lexema hebreo devorím por <abispas> en lugar de por /abežas ${ }^{64}$ como figuraba en los anteriormente mencionados versículos del Pentateuco. No es, pues, extraño que esta simplificación léxica tuviera lugar primero entre los rabinos y hombres que estudiaban en las escuelas judias, puesto que alli era donde especialmente se usaban glosarios como el de Moisés Cordovero. También cabe la posibilidad de que el propio Cordovero incluya en su glosario una única forma por haberse perdido ya en la sociedad sefardí, o en parte de ella, la distinción entre ambos insectos y que la conservación de la distinción en las Biblias ladinas del siglo xy se deba precisamente a que la base de esas traducciones está en las que se habian hecho en la Península siglos atrás. En 1568 el autor del Séfer Šulhán Hapanim yamado en ladino Meza del Alma aún incluía el término /abeyas $/{ }^{65}$.

En un diccionario ${ }^{66}$ "hebreo bíblico - judeoespañol" editado por los misioneros protestantes en 1855 en Estambul, los dos sustantivos hebreos son traducidos por "abizba o abeža" y por "abižon o avispon, ke es komo abiz$b a$, ma mucho mas grande", de cuya explicación podemos extraer que /abízba/ se usaba ciertamente con más frecuencia que /abéža/. En la tra-

\footnotetext{
${ }^{60}$ Ladino Pentateuch, Estambul 1547, Devarim (= Desteronomio) 1:44.

${ }^{61}$ Ladino Pentateuch, Estambul 1547, Šemóđ (= Éxodo) 23:28 y Devarim (= Deuteronomio) 8:20.

${ }^{62}$ Cof. los versículos citados en la nota anterior en Hélek rišón mehaarbá veesrim vehú hamišá humšé torá im laaz, Constantinopla, 1739.

${ }^{63}$ Cof. los versículos citados en Séfer arbaá veesrim hélek rišón, Viena, 1813.

${ }^{64}$ Cfr. Bunis, «Tres formas de lađinar la Biblia...», pág. 329, donde se refiere a Tehilim (= Salmos) 118:12

${ }^{65}$ Véase allí, págs. $24 \mathrm{v}$ y $36 \mathrm{v}$.

${ }^{66}$ W. Goattieb Šauffler, OSár Divré Lešón Hakódeš. Constantinopla 1855, entradas "detorá" y "siir'á" en hebreo, por este orden.
} 
đucción de la Biblia al judeoespañol realizada por la misión protestante en 1872 que está bastante lejos de atenerse a los cánones tradicionales del ladinar sefardí, encontramos únicamente la forma $<$ abisba $>0<a b i z b a>67$, tanto para 'abeja' como para 'avispa', lo cual prueba que la simplificación estaba si no totalmente consumada, sí ya ampliamente difundida entre todas las clases sociales sefardies de Estambul. En esta simplificación formal puede haber influido también la lengua turca, por ser identificados ambos insectos con <arıs1>. En Estambul además de la voz /bizba/ para 'abeja', los sefardíes empleaban <bizba>, <bizba vahşiya> (= avispa salvaje), y <eşekarıs〉> (= avispa de asno) para 'avispa'. La forma residual /abižón/ de Esmirna, representa el resultado de un segundo proceso de reducción semántica por pérdida nuevamente de la distinción entre los dos referentes.

Todo parece indicar que primero hubo una simplificación semántica por confusión entre ambos referentes. Por asociación se crearon dos nuevos denominativos derivados de las respectivas bases /abeža/ y "abizba" añadiendo el sufijo -ón que denota mayor tamaño, restableciéndose de nuevo la distinción entre las formas terminadas en $-a$ para denominar la 'abeja' y las formas terminadas en - on para la 'avispa' por poseer este insecto mayor tamaño ${ }^{68}$.

\section{8. /(z)inzias - yinŷivres/}

Lat. GINGİVA.

Las tres formas sefardies tienen como respectivas bases etimológicas las formas castellanas /ensias/ $</$ ensiias $^{69}$ y /ensivas/ ${ }^{70}$ y la portuguesa [žēeží:ves] ${ }^{71}$ con las correspondientes variantes occidentales (del leonés y del gallego). A este respecto, hay que mencionar la forma /ženžíbres/ que se conserva aún en Hermisende ${ }^{72}$, localidad de habla leonesa.

Los cambios fonéticos que tuvieron lugar en las formas sefardies tienen fácil explicación: el cambio que se produce en la última sílaba de [žẽěžíves]

\footnotetext{
${ }^{67}$ Cfr. El Livno de la Ley, los Profetas $i$ las Eskrituras, Constantinopla, Empremeria de A. H. Boyaçan, 1872, los versículos de Šemóđ (= Éxodo) 23:28 y Devarím (= Deuteronomio) 8:20.

${ }_{68}$ Formas de aumentativo que denota tamaño son frecuentes en la Peninsula Ibérica. Sin embargo, con abejón se designa a una abeja que molesta mucho o al zángano del enjambre. Otro tanto se puede decir de avispón que, más que referirse a su tamaño, denota la molestia que su presencia causa.

${ }^{69}$ Roger Wright, Latin tardio y romance temprano. En España y la Francia carolingia. Madrid, Gredos, 1989, pág. 33.

${ }^{70}$ Esta forma aparece también en la literatura medieval castellana, entre otros lugares, en el Libro de Buen Amor del Arcipreste de Hita (siglo xiv).

${ }_{71}$ Cfr. Lloyd, Del latín al español... págs. 398-399. [žẽě̌i:vás] parece haber estado bastante extendida en toda la parte occidental de la Península Ibérica, puesto que también en la zona de habla leonesa se conocen formas más arcaicas que la castellana.

${ }^{72}$ Alonso Zamora Vicente, Dialectologia Española, Madrid, Gredos, 1985, pág. 134.
} 
que pasa a fyinŷibres/ o fyinŷivres/ en la mayoría de las variedades sefardies, viene ocasionado por la presencia del vocablo /yinŷibre/ o /ŷenyíbre/, jengibre en castellano, en el sistema léxico del judeoespañol, forma documentada en Salónica, Estambul, Jerusalén y Bucarest. Lo que no es seguro es si este cambio se produjo en el ámbito sefardi o si ya había tenido lugar antes de la expulsión. La existencia de /ženžíbres/ (= encías) en Hermisende nos puede llevar a suponer que la forma sefardí fue importada de la Península Ibérica, aunque más probable parece que haya surgido por influjo de <yenŷibre>, (= jengibre), documentado en Salónica en $1568^{73}$ frente a $<$ enŷibas $>(=\text { encías })^{74}$.

En Ias comunidades sefardíes de Estambul y Jerusalén que cuentan con la forma /(z)inzias/, la bilabial oclusiva de /ŷinŷibre/ (= jengibre) pasó a pronunciarse como fricativa, es decir, /ŷinŷibre/, lo cual concuerda perfectamente con la pronunciación sefardí generalizada de /b/ delante de vibrante. La forma /zinsías/ que aparece al lado de /inzías/, está ocasionada por el acoplamiento del morfema de número $\{-\mathrm{s}\}$, a veces realizado como [-z], al nombre, debido a que este sustantivo suele ser usado en plural.

Llama especialmente la atención el adelantamiento de la acentuación de /énzjas/ en Castoría, quizás por influencia de /ánsjas/, así como el uso de /ŷinŷivres/ con artículo masculino en la comunidad de Sofia, para cuya explicación propongo también una influencia del uso de /ŷinŷibre/ (= jengibre) con artículo masculino.

\subsection{Bostezár - bostežár/}

Lat. OSTYCARE con $b$ - protética por influjo de BOCA

La forma /bostezár/ se corresponde con la castellana ampliamente difundida en el centro y este de la Península Ibérica, mientras que las lenguas occidentales (portugués, gallego y asturleonés) contaban con /bosežár/. La forma /bostežár/ parece una forma interdialectal, que conservó la raiz castellana acoplada a la pronunciación portuguesa. No la encontramos documentada en textos medievales ibéricos. En textos de Salónica del siglo xvI encontramos $<$ bosesen $>{ }^{75}$, procedente de la forma medieval registrada en castellano $<$ bocezar $>^{76}$, pero con confusión de la sibilante, fenómeno que

${ }^{73}$ Séfer Sulhán Hapanim yamado en ladino Meza del Alma, pág. 36.

${ }^{4}$ Íd., pág. 96.

${ }^{75}$ Cfr. Almosnino, Livro entitulado rềimyento dela vida, Salónica, 1564, pág. 35v donde aparece <... ke no eskupan ni bosesen... .

${ }^{76}$ Cfr. J. Cejador y Frauca, Vocabulario medieval castellano, Madrid 1929 (Reimpr. en Heildelberg - Nueva York, Olms, 1971), pág. 74. 
por aquel entonces era propio del castellano culto del Norte de Castilla, y encontramos también <bosteze $>77$, la forma castellana culta.

La distribución diatópica de ambas formas sigue claramente la onda expansiva de influencia de los dos grandes centros culturales hasta el siglo xvII. La presencia de /bostežár/ en Jerusalén confirma, además, la influencia de la lengua de Salónica sobre la de la comunidad de Jerusalén, a la que constantemente llegaban sefardíes de ésta y otras comunidades; especialmente en el siglo xVIII hubo una emigración importante de sefardíes procedentes de la comunidad de Salónica. En Esmirna encontramos ambas formas, anotadas por Révah y K. Levy ${ }^{78}$ respectivamente, de boca de hablantes nacidos a finales del siglo XIX. Como en otros casos, observamos también aquí una estrecha relación lingüistica entre el judeoespañol de Salónica y el de Esmirna. Recordemos que esta comunidad, fundada en $1605^{79}$, empieza a alcanzar importancia en el siglo XVII con la llegada de anusim, pero también de sefardies procedentes de Salónica ${ }^{80}$, lo cual explica bastante bien la presencia de formas léxicas salonicianas en el judeoespañol de dicha comunidad. En 1620, tres de sus seis sinagogas estaban administradas por judíos procedentes de Salónica ${ }^{81}$.

\subsection{0. /(a)granáda - mangránal}

Cada una de las formas tiene la siguiente procedencia:

a. /granáda/ es la forma castellano-portuguesa.

b. /mangrána/ es voz catalano-aragonesa.

Ambas derivan de grano, pero por asociaciones diferentes. El sustantivo/granáda/ procede del adjetivo granado/-a, es decir, 'lugar u objeto con muchos granos', cuyo uso como sustantivo acabó por lexicalizarse. /magrána/ o /mangrána/ derivan de 'mil granos' ${ }^{82}$, aunque una

$"$ Séfer S̆ulhán Hapanim yamado en ladino Meza del Alma, pág. 18.

${ }^{78}$ En el primer caso, se trata de una información proporcionada por Ester Arditi, nac. en 1875, según se encuentra anotado por Révah (mss. del archivo personal de Révah). Para la segunda forma se puede consultar Kurt Levy, «Historisch-geographische Untersuchungen zum Judenspanischen. Texte, Vokabular und grammatische Bemerkungen', Volkstum und Kultur der Romanen, vol. 2, Hamburgo, 1929-30, pág. 368 .

${ }^{79}$ Révah, "Formation des parters judéo-espagnols: Comparaison avec la formation des parlers brésiliens», Anais do Primeiro Simpósio de Filologia Românica, Rio de Janeiro, 1970, pág. 151.

${ }^{80}$ E. Benbassa y A. Rodrigue, Juifs des Balkans, págs. 70 y 109.

${ }^{81}$ Révah, «Formation des parlers judéo-espagnols...», pág. 151.

82 Cfr. J. Corominas y J.A. Pascual, Diccionario..., vol. III, Madrid, Gredos, 1980, pág. 198, pues la forma milgrana está documentada también en textos castellaros y aragoneses. Mangrana es la forma usual en aragonés y catalán hasta el presente. En mozárabe también se empleaba magraneš, según afirma A. Galmés de Fuentes, "Mozárabe", M. Alvar, Manual de diactologia hispánica. El Español de España, pág. 109. 
asociación con 'manzana de granos' ( $<$ MALUM GRANATUM), parece más admisible ${ }^{83}$.

El reparto diatópico de ambas formas en judeoespañol presenta un aspecto muy regular: por una parte, la forma catalano-aragonesa domina todas las comunidades occidentales, inchuida Salónica, mientras que la forma castellano-portuguesa fue la que se impusó en Estambul y en las comunidades orientales. Debemos de añadir que en Salónica /granáda $/{ }^{84}$ es forma conocida, aunque menos usada que /mangrána/, como señala Nehama ${ }^{85}$, de la que también procede /mangranéro/ ${ }^{86} \mathrm{o}$ 'árbol de la mangrana', derivación denominal, sin duda, judeoespañola. La forma con $a$ - protética de Estambul, Esmirna y Bursa se explica por la fusión de la vocal del artículo la con el sustantivo, lo cual también sucedió en otras voces, entre las que podemos mencionar asofáyfa $(\mathrm{a}+$ sofayfa $)$, amóra $(\mathrm{a}+\mathrm{mora})^{87}$.

\subsection{1. lasúkar - sukrel}

Árabe. as-sūkkar. Cast. y port. asucar. Cat. y arag. sucre.

Las formas sefardies son, por una parte, la castellano-portuguesa /açúkar/ y, por la otra, la catalano-aragonesa /súkre/. /asúkar/ la encontramos tanto en Salónica como en Estambul, frente a /(a)súkre, asúkri, asúker, asúkir/, difundidas en las comunidades del interior de los Balcanes, aunque en algunas (Sofia, Monastir, Bucarest) coexisten varias formas derivadas de los étimos referidos.

Descartada una influencia de las lenguas coterritoriales, estas formas del interior de los Balcanes poseen un origen común, es decir, la forma catalono-aragonesa sucre, forma que probablemente coexistió durante algún tiempo también en Salónica, al lado de asúkar. Las formas /asúkir/ y /asúker/ son formas interdialectales surgidas por acomodación entre las formas /asú$\mathrm{kar} / \mathrm{y} / \mathrm{súkre/.} \mathrm{En} \mathrm{las} \mathrm{comunidades} \mathrm{del} \mathrm{interior} \mathrm{de} \mathrm{los} \mathrm{Balcanes,} \mathrm{el} \mathrm{proceso}$ de acomodación de estas formas aún no se ha cerrado, como lo muestra el polimorfismo existente.

Destacable es la pérdida de la vibrante final $-r$ en esta palabra en la lengua hablada de Salónica, lo cual ocurre igualmente en Monastir, probablemente por contacto con las respectivas lenguas coterritoriales, aunque este fenómeno es también conocido dentro del ámbito castellano.

\footnotetext{
${ }^{83}$ J. Corominas y J. A. Pascual, Diccionario..., vol. III, Madrid, Gredos, 1980, pág. 197.

${ }^{84}$ Es la forma que figura en Sedér Našm, Salónica (s.a., pero antes de 1568), pág. 290

${ }^{85}$ Cfr. Neharna, Dictionnaire ..., pág. 229 bajo granáđa.

${ }^{86}$ Nehama, Dictionnaire .... pág. 342.

${ }^{87}$ Wagner, Beiträge..., pág. 144, § 130.
} 


\subsection{2. /kóla - kódal}

Lat. vg. $\bar{\omega} \overline{D A}$.

Tanto la forma $/ \mathrm{kóda} /$ como /kóla/ proceden de la Península Ibérica. Sin embargo, en $1492 / \mathrm{kóla} /$ era ya poco frecuente en la zona castellana, mientras que / kóda/ se continuaba y continúa empleando en aragonés. En la lengua sefardí encontramos ambas formas, pero con una distribución geográfica concreta que se corresponde perfectamente con las áreas de influencia de las dos grandes comunidades, Salónica y Estambul. /kóda/ aparece en Salónica en un texto del siglo $\mathrm{XVI}^{88}$, lo cual confirma la coexistencia de ambas formas allí en el siglo XVI; nuestra afirmación se deduce de la presencia de $/ \mathrm{kóla} /$, como única forma, en Sarajevo, pues, como ya mencionamos, la comunidad de Bosnia fue fundada por judíos procedentes de Salónica en la segunda mitad del siglo XVI. Una vez más, Salónica fue el centro de irradiación de una forma, en este caso /kóda/.

\subsection{3. /kwidádo - kudjádo/}

La forma / kwidár/ remite no sólo a la forma castellana, sino también a la portuguesa y a la gallega. Por el contrario, la forma /kudjár/ es considerada vulgarismo en las pocas áreas en las que aparece dentro del espacio iberorrománico, fuera de la zona aragonesa, desde donde probablemente fue llevada al Imperio Otomano. La presencia de / kwidado/ en Monastir y Sarajevo, además de en Salónica, apunta hacia la posible convivencia de ambas formas, al menos, en Salónica, desde donde la forma /kuđjáđo/ sería llevada a las comunidades de Sofía y Vidín a través de las cuales se realizaba el comercio hacia el Danubio oriental. La forma /kudjózo/ de Bucarest se puede explicar por el hecho de que la mayoría de los sefardíes fundadores de la comunidad en esta ciudad procedian de Turquía. La forma /kudjádo/ de Belgrado puede haber sido llevada de Vidín y de Sofía debido a las estrechas relaciones mantenidas entre estas comunidades.

\subsection{4. lagartéža - gartižal}

Derivado de lagarto < lat. * LACARTUS < LACĔRTU. Arag. med. lagartiža.

La forma sefardi /lagartiža/ con todas sus variantes se considera de origen aragonés ${ }^{89}$, mientras que en castellano y en portugués en 1492 se empleaba

\footnotetext{
${ }^{8}$ Séfer Šulhán Hapanim yamado en ladino Meza del Alma, pág. $129 \mathrm{v}$.

${ }^{89}$ Cfr. Corominas y Pascual, Diccionario... vol. III, 1980, pág. 557, por ser en Aragón el primer lugar donde tuvo lugar la confusión entre sordas y sonoras.
} 
/lagartiša/. En las Biblias sefardies la palabra hebrea correspondiente no se tradujo, de manera que solamente en la Biblia de Ferrara ${ }^{90}$ encontramos $<$ lagartija>, que puede corresponderse con la forma žižeante, aunque parece más probable interpretar que se trata de la grafia portuguesa de la época, pero que ya se pronunciaba como šišeante.

La pérdida de la primera sílaba $l a$-, puede haber tenido lugar dentro del ámbito sefardí por confusión de ésta con el artículo femenino. Sin la- nos es desconocida en la Península Ibérica, pero en judeoespañol aparece ya $<$ garto $>^{91}$, reducción de lagarto, en un texto de medicina popular de finales del siglo $\mathrm{XVI}$, con lo cual no se debe descartar tampoco la posibilidad de que la forma existiera ya antes de la expulsión en algún habla local. Las formas con $-n$-, es decir, /langartiža/ y /langritéža/ se corresponden con formas catalanas ${ }^{92}$. /langartiža/ parece haber adquirido, además, el significado de 'escorpión' en Belgrado.

En Castoria la forma castellana fue sustituida por una forma griega ${ }^{93}$, de igual manera que la probable forma anterior /sambašuga/ lo fue por una forma veneciana. En Belgrado, parece ser que, además, de haberse conservado formas de origen aragonés y catalán, en los últimos años se produce una confusión entre /samšúga/ y /langertíža/ o /gritíža/. La misma confusión se puede haber dado en Sarajevo, puesto que Romano, traduce las formas

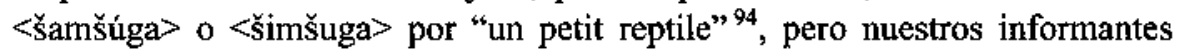
sólo conocen /lagartiža/. Por su parte, Subak y Baruch recogieron allí/samišuga $/{ }^{95}$ y $/$ šam(i)šúga $/{ }^{96}$ respectivamente con el significado de 'sanguijuela', pero no con el de 'lagartija'.

Podemos concluir este capitulo afirmando que las formas léxicas y lexemas analizados representan variantes geográficas de la koiné sefardí en la que han sobrevivido:

a) variantes de la mezcla original: (/ferožénto - furužěnto/, /(f)igado (f)égado/, /dóẑe, tréẑe - dóze, tréze/, /mursjégano - mursjégo/, /lónŷe -

\footnotetext{
${ }^{90}$ Cfr. Biblia de Ferrara, Ferrara, 1553, Veyikrá (= Levítico) 11:30.

91 Cfr. Crews, "One Hundred Medical Recipes in Judeo-Spanish of ca. 1600», Revie des Etudes Juives 126, 1967, págs. 225 y 245.

${ }^{92}$ Cfr. Corominas y Pascual, Diccionario..., vol. III, 1980, pág. 557.

${ }^{93}$ Cfr. Wagner, "Los dialectos judeoespañoles de Karaferia, Kastoria y Brusa», pág. 201, del griego moderno yovotepitoo.

94 Romano, op. cit., pág. 300.

95 Julius Subak, «Zum Judenspanischen». Zeitschrift für Romanische Philologie, XXX, 1906, pág. 171.

${ }_{96}$ Kalmi Baruch, "Der Lautstand des Judenspanischen in Bosnien», Tesis de Doctorado en la Universidad de Viena, 1923, pág. 10.
} 
léšos/, /sanŷwéla - sangrwéla - sanguŷwéla/,/enzias/, /bostezár/, /mangrána - (a)granáda/, /sukre-i - asúkar/, /kola - koda/, /kwidádo - kudjádo/, /lagartíža/),

b) formas interdialectales: (/dóŷe, tréŷe/, /enteýár/, /bostežár/, /sanŷuwéla - sanŷigwéla - šam(i)šúga - šambašúga/, /bézba - bézba/, /(a)súker - (a)súkir/, /langartíža - langritéža/),

c) formas nuevas no necesariamente creadas durante el proceso de acomodación, sino posteriormente: (/ŷinŷives, ŷinŷivres, zinzías/, /sanŷurwéla sanŷirgwéla - sanŷirwéla/, /asúkwar/, /gritiže, gartiža, gartéža/),

d) formas nuevas creadas por derivación (bezbón, aちižón/) o por composición (/papasjéga/: Sus. + Adj.).

e) adstratos: (/sangwéta/, /kostériša/ y /sy:ly:k/) de incorporación más reciente.

En muchos casos, en una misma variedad conviven varias variantes de una misma forma, es decir, que el proceso de nivelación aún no concluyó ${ }^{97}$ (BURSA Y ESTAMBUL: /ferožénto, furožénto/; SALóNICA: /mursjégo, mursjégano/; BURSA: /sanŷigwéla, sangrwéla/; ESTAMBUL: /sanŷirwéla, sanŷirgwéla/ JERUSALÉN: sanŷurwéla, sangužwéla/; ESMIRNA: /bostezár, bostežár/; SALÓNICA: /mangrána y granáda/; SARAJEVo Y BUCAREST: /asúkir, asúkri/; BELGRADO: /asúkre, asúkar/; MONASTIR: asúker, asúkar; SOFIA: /asúkir, asúkar/), entre otras.

En muchos de estos casos, se puede hablar de polimorfismo, pero en otros se trata de variantes estilísticas (ESTAMBUL y BURSA: /ferožénto/ en el nivel culto frente a /furužénto/ en el nivel más popular; ESTAMBUL: /dóze/ en el nivel muy culto y /dóŷe/ en nivel intermedio y popular; SALÓNICA: /granáda/ en ladino y /mangrána/ en todos los niveles del judeoespañol).

\section{IMPOSIBILIDAD DE ESTABLECER GRUPOS DIALECTALES SEGÚN CRITERIOS LÉXICOS}

Del presente estudio podemos extraer varias conclusiones. La más relevante es la imposibilidad de establecer grupos dialectales del judeoespañol

\footnotetext{
${ }^{97}$ También conviene tener presente que los judios sefardies formaban un grupo social muy dinámico: por un lado, los que se dedicaban al comercio solían desarrollar sus actividades en varias comunidades $y$, por otro, también solian realizarse matrimonios entre miembros de diferentes lugares, lo cual facilitaba el tránsito de variantes lingüísticas de un lugar a otro. No sería, por tanto, exagerado suponer que en algunos casos el políformismo sefardi resulte más aparente que real, puesto que alguna de las formas registradas podría estar limitada al uso de una persona o de una única familia con algún miembro procedente de otra comunidad.
} 
siguiendo criterios léxicos, como sí había sido posible en nuestro estudio fonológico anterior. Cuando comparamos el recorrido de los isofonos y de los isolexos correspondientes a cada una de las formas y lexemas analizados, su resultado no es el esperado haz de isoglosas que nos proporcionaría con mayor o menor claridad diferentes grupos de variedades lingüisticas.

Por el contrario, como ya mencionamos antes, se pueden observar procesos de acomodación y nivelación entre los elementos de los diferentes dialectos y lenguas de la misma familia, en todos los casos se trata de lenguas románicas. La lengua de cada comunidad sefardí representa una koiné en la que participaron dialectos mutuamente comprensibles llevados por sus hablantes de sus respectivos lugares de origen (si contemplamos esta pequeña muestra léxica en cada una de las trece comunidades sefardies analizadas, rápidamente observaremos que casi siempre se da variación de una a otra).

$\mathrm{Si}$ aplicamos el concepto de teoría de las ondas, sí podemos observar la influencia ejercida desde Sạlónica y Estambul, hasta el siglo XVIII los dos centros culturales sefardíes en el Imperio Otomano, sobre el resto de las variedades sefardies. La onda expansiva correspondiente a cada forma o lexema alcanza su particular dimensión, por lo que, al menos en algunos casos, es posible fijar el punto de partida de cada una de ellas. Para las comunidades fundadas en los siglos posteriores a la expulsión por judíos procedentes de las primeras comunidades sefardíes creadas en el Imperio Otomano, no siempre es posible establecer una relación entre la variedad lingüística de su lugar de origen y la variedad desarrollada en la nueva comunidad. Un buen ejemplo de ello lo encontramos en la comunidad sefardi de Bucarest, creada en el siglo XVIII por población que mayoritariamente procedia de Estambul. Sin embargo, las formas y voces analizadas difieren más de las usadas en Estambul que de las empleadas en las comunidades de su entorno en zona eslava. De trece formas y lexemas, doce coinciden en el judeoespañol de Vidín y en el de Bucarest. La primera de ellas, ciudad situada a orillas del Danubio, fue hasta el siglo XIX el lugar de paso más importante en la ruta comercial desde Salónica hacia el este de los Balcanes y ejerció, sin duda alguna, un importante papel en la transmisión de formas lingüísticas a los centros sefardíes vecinos (Craiova, Bucarest, Turnu-Severín o Ruse). Debemos añadir, además, que un buen número de rabinos que ejercieron en las ciudades vecinas procedía de familias de Vidín. Indudablemente, factores extralingüisticos contribuyeron de manera notable a la expansión de fenómenos lingüísticos dentro de una comunidad concreta en un determinado momento de su historia, como se corrobora también en la relación existente entre las variedades sefardies de Esmirna y las de Salónica y Estambul. Según los lexemas y formas inventariadas aquí, la lengua sefardí de la comunidad de Esmirna ocupa un lugar intermedio entre la len- 
gua de Estambul y la lengua de Salónica. Ello se debe a la afluencia de población sefardí procedente de Salónica hacia Esmirna en el siglo XVII, hecho motivado por cuestiones socioeconómicas, en particular por la caída de la industria textil en la ciudad griega. Encontramos en Esmirna las formas /ferožénto, morsjégano, zinzívas, bostežár, gartéža, sanŷuwéla/, sin duda, llevadas desde Salónica.

Movimientos migratorios entre las comunidades sefardies como el señalado, unas veces voluntarios o resultado de hechos económicos y otras ordenados por el gobierno otomano, suponían la puesta en marcha de un nuevo proceso de nivelación lingüistica en el lugar de llegada, abrian la posibilidad del cambio de dirección de algunas de las innovaciones pendientes de definición. En muchos casos, las innovaciones se cerraron con la elección contundente de una de las formas candidatas (/sanŷuwéla/ sobre/sanbesú$\mathrm{ga}$, esta última registrada todavía en textos de medicina de Esmirna de finales del siglo XIX). Pero en otros casos, el proceso de selección no se cerró nunca, como se explica a través de la convivencia de varias formas en una misma comunidad hasta nuestros días; en Salónica, no por ser usados con más frecuencia los lexemas /lónŷe, mangrána/ y la forma /bostežár/, dejan de ser conocidos /léšos, granáda/ y /bostezár/.

El léxico del judeoespañol de Salónica posee mayor número de elementos no castellanos cultos o de origen culto (diez de trece casos) que el de Estambul (solamente tres) ${ }^{98}$. Sin embargo, según esta pequeña muestra del componente léxico sefardí, no es posible establecer una relación genealógica directa entre la variedad de Salónica y una lengua o dialecto concreto de la Península Ibérica, lo cual tampoco es posible para otras variedades del judeoespañol, en contra de las afirmaciones varias veces repetidas hasta los años cincuenta del pasado siglo ${ }^{99}$, corregidas por investigadores posteriores ${ }^{100}$.

\footnotetext{
${ }^{98} \mathrm{La}$ voz /lagartiža/ y otras formas afines, están incluidas en ambos recuentos, por haber triunfado en sendas comunidades sobre la forma castellana /lagartíš/, mientras que dejamos fuera del recuento la voz /mursyégano/ y sus variantes, por ser considerada forma castellana que se conserva en el habla dialectal y popular.

${ }^{99}$ Cfr. A.S. Yahuda, "Contribución al estudio del judeo-español», Revista de Filología Española, vol. II, 1915, págs. 351-352 y Wagner, «Algunas observaciones generales sobre el judeoespañol de Oriente», Revista de Filologia Española, vol. X, 1923, pág. 240, íd., Caracteres generales del judeo-español de Oriente. Anejo II de Revista de Filologia Española, 1930, págs. 21-22 y «Espigueo judeo-español», Revista de Filología Española, vol. XXXIV, 1950, págs. 9-10.

${ }^{100} \mathrm{Cfr}$. Révah, «Formation et évolution...», Paris, 1965, pág. 1354 y id., «Formation des parlers judéo-espagnols...», pág. I51; Quintana, "Dialektologie...", págs. 103-108 y id., «Diatopische Variation....», păgs. 57-58; Laura Minervini, Testi Giudeospagnoli Medievali (Castiglia e Aragona), vol, I, Napoles, Liguori Editore 1992, págs. 142-144, y id., «The Formation of the Judeo-Spanish Koiné: Dialect Convergence in the Sixteenth Century", The Proceedings of the Tenth British Conference on Judeo-Spanish Studies, 29 June - 1 Ruly 1997, editado por A. Benaim, Londres, Queen Mary and Westfield College, 1999, pág. 48; Bunis, «Phonological Characteristics of lbero-
} 
El proceso de nivelación lingüística que se inició con el encuentro de sefardíes que hablaban diferentes lenguas, dialectos o variedades mutuamente inteligibles en Salónica, en Estambul o en las otras comunidades creadas después de la expulsión de 1492, aún estaba lejos de concluir a finales del siglo $x v{ }^{101}$. Sirva para ilustrarlo la conservación de las formas /figado, léšos, kóla/ en el judeoespañol de Sarajevo, comunidad creada por sefardies procedentes de Salónica en la segunda mitad del siglo $x v 1{ }^{102}$, después que en 1581 las autoridades turcas autorizaron la construcción del primer barrio judio ${ }^{103}$, permitiéndose con ello el asentamiento alli de un importante número de familias de Salónica. Estas formas conservadas hasta nuestros dias en Sarajevo son las que figuran en todos los textos sefardies editados en Salónica en el siglo XVI, pero que compitieron posteriormente con otras no castellanas /ónŷe, fégado, kóda/, incluso en la lengua escrita, para terminar por ser sustituidas por éstas. Este punto nos confirma la convivencia de varias lenguas (castellano, aragonés, portugués más tarde) e incluso de varias nommas del castellano ${ }^{104}$, en Salónica durante las primeras generaciones después de la expulsión, situación que no debió de ser diferente en otras comunidades creadas inmediatamente después de 1492.

Con referencia a la lengua sefardi del siglo xv afirma Révah que "...bien des Juifs non castillans devaient déjà parler en 1492 la langue dont la suprématie politique et littéraire s'affirmait dans la Péninsule, à savoir le castillan" ${ }^{105}$. Si ello fuera correcto, el proceso de nivelación habría sido más breve $y$ las formas vulgares, dialectales y procedentes de otras lenguas dificilmente habrian pervivido, en contra de lo que nos muestra la realidad lingüística sefardí especialmente a partir del siglo XVIII, cuando las variedades de los dos grandes centros habian adquirido personalidad propia. La afirmación de Révah tiene, en cambio, relevancia con relación a la clase intelectual sefardí y con relación al uso del castellano como lengua intercomunitaria. No hay lugar a dudas de que, en la Península Ibérica, el castellano era ya la lengua en la que la clase intelectual judía se expresaba en el contacto entre las diferentes comunidades, de igual manera que lo hacia la clase culta cristiana. Como

\footnotetext{
Romance Elements in the First Printed Ladino Bible Glossary (Séfer Hešeq Selomo, Venice, 1587/88)", Hispano-Jewish Civilization after 1492. Proceedings of Misgav Yerushalayim's Fourth International Congress, 1992, editado por M. Abitbol, Y.T. Assis y G. Hasan-Rokem, Jerusalén, Misgav Yerushalayim, 1997, págs. 224-225, y Ralph Penny, «Judeo-Spanish varieties before and after the Expulsion", Donaire, núm. 6, Londres, Embajada de España, 1996, págs. 55-56.

${ }^{101}$ Minervini, «The Formation of the Judeo-Spanish Koiné..,», pág. 48.

${ }^{102}$ Moritz Levy, Die Sephardim in Bosnien. Sarajevo, 1911, pág. 4 y también August Kovačeć, "Les Séphardim en Yougoslavia et leur langue. D'après quelques publications yougoslaves», Studia Romanica et Anglica Zagrabiensia, núrs. 25-26, 1968, pág. 165.

${ }_{103}^{10}$ Moritz Levy, Die Sephardim in Bosnien, Sarajevo, pág. 11.

${ }^{104}$ Buris, "Tres formas de ladinar la Biblia...», pág. 342.

${ }^{105}$ Révah, «Formation et évolution...», Paris, 1965, pág. 1353.
} 
se desprende de los textos sefardíes del siglo XV, tanto de Salónica como de Estambul, la lengua de los rabinos, además del hebreo ${ }^{106}$ era una variedad iberorromance más próxima a la castellana de Toledo que a ninguna otra. De ello da fe el importante número de obras publicadas en esta lengua, mientras que no contamos con literatura escrita en catalán, aragonés o portugués. Cuando los rabinos se querían dirigir a grupos más amplios de sefardíes, lo hacian indudablemente en dicha variedad castellana, porque ésta era la lengua de cultura de la clase dominante y de la clase intelectual ${ }^{107}$. Incluso cuando los rabinos dirigieron sus obras escritas a un público vasto, lo hicieron en esta lengua, pero siendo obligados a incluir en ella formas más populares ${ }^{108}$ que volveremos a encontrar ya como parte integrante del léxico sefardí en todos los textos posteriores al siglo xvnI. Ello no quiere decir que de la comunicación privada y de la comunicación de cada comunidad desaparecieran inmediatamente las respectivas lenguas llevadas de la Península. La pervivencia, aunque no numerosa, de formas y voces no castellanas, que aparecen de manera general en el aragonés medieval, incluidos los textos escritos por judíos y que en su mayoría se conservan en la fabla aragonesa actual (/atorgár, prévar, fešúgo, péše, lónso, lagartiža, tobáža, bóĉa, repwésta, moléžas, niñéta del ožo, gizandéra, kazál, kazalino, anáda, mezáda, semanáda, abantaže, feguza, esnóga de mužéres (lugar destinado a las mujeres en la sinagoga), taraláña (tanto para araña como para telaraña), enemígo (padrastro, respigón), çíko, fešúgo, (d)eskorçár (desollar), mesturár, mokárse (sonarse), pišárse (orinar), romanesér (permanecer), trezladár/) 109 en todas las comunidades sefardíes, y de otras en algunas de ellas (/man-

\footnotetext{
106 No debemos de ignorar en este punto el papel jugado por la lengua hebrea en el seno de las cornunidades sefardies, especialmente entre los sabios, lengua en la que publicaron la mayor parte de sus obras.

${ }_{107}$ El rabino Mošé Almosnino (Salónica 1518-? 1579), de padres catalano-aragoneses cultivó el lenguaje literario más castellano de cuantos se dieron en Salónica a mediados đel siglo XvI, a pesar de haber ocupado el cargo de rabino en la comunidad de los catalanes a la que pertenecía su familia, desde 1551 y de los marranos portugueses desde 1560. Sin embargo, en su Livro entitulado reŷ́imyento dela vida (1564), la influencia del catalán apenas dejó huella, cf., I.S. Révah, "Le lexique de M. ALMOSNINO. Contribution à l'histoire du castillan". Mémoire présenté pour l'obtention du diplôme de l'Ecole pratique des Hautes-Etudes Vection, 1954, págs. 22-26 y 222.

${ }_{108}$ Ej Séfer Sulhán Hapanim yamado en ladino Meza del Alma, Salónica 1568, y el Séfer Hešeq Selomó, Venecia, 1588 , aun tratándose de obras relacionadas con las traducciones del hebreo, son buenos ejemplos al respecto. Las declaraciones en la lengua hablada insertadas en los responsa del siglo xvı son a nuestro modo de ver las que mejor reflejan algunas tendencias dialectales y populares, sin dejar por ello de estar escritas en castellano, lo cual tiene dos explicaciones: por una parte, el castellano era lógicamente la lengua de los escribanos de los Tribunales Rabínicos; por otra parte, el castellano aparece ahí como la lengua intercomunitaria.

${ }^{109}$ Quintana, «Concomitancias lingüísticas entre el ladino (judeo-espariol) y el aragonés», Archivo de Filologia Aragonesa, LVII-LVIII, 2002, págs. 163-192.
} 
grána, súkre, kóda, fortúna (= 'tempestad'), kudjádo, botiga, lugo/) ${ }^{110}$ pone de manifiesto que dicha variedad fue la hablada por los judios procedentes del Reino de Aragón durante las primeras generaciones y, por tanto, algunas de sus formas léxicas y lexemas compitieron con las correspondientes castellanas en la comunicación diaria. Con el inicio de la llegada masiva de portugueses después de $1536^{111}$ y especialmente después de $1549^{112}$, comenzaron a entrar en juego también formas y lexemas de su lengua (longe [lõ:žo], sanbessuga [sẽbə'su:ge] o [sēbə'šu:ge], vespa [béspa], gengivas [žě'ží:ves], bocejar [busə'ža:r]).

Debe de quedar bien claro que entre las lenguas habladas y la lengua escrita a lo largo del siglo xvi y, por lo menos, parte del xvII se dio una fuerte discrepancia por el hecho de que la clase intelectual sefardí intentó emplear solamente el castellano, en la medida que aún le era posible, en su producción textual, naturalmente que también se expresó en la lengua hebrea. Este papel del castellano se debe precisamente a que el contacto entre los diferentes kales (sinagogas) se continuó realizando en esta lengua como se practicaba ya antes de las expulsiones de la Península Ibérica, debido ya a su prestigio como lengua de cultura.

Por otra parte, cada grupo se mantuvo agrupado en torno al $\mathrm{kal}$ de acuerdo a su origen de procedencia ${ }^{113}$ y continuó empleando su lengua de origen en la comunicación privada, como ya afirmamos. Todo ello produjo una unificación del habla relativamente lenta en favor de una norma estándar. Cuando a mediados del siglo XVIII comenzó a desaparecer este tipo de estructura social dando paso a comunidades más homogéneas, fue cuando también se configuró la personalidad lingüística de cada koiné sefardí en las comunidades hasta entonces existentes, desapareciendo definitivamente el aragonés y quedando relegado el uso del portugués a la comunicación privada entre las familias que aún estaban llegando de Portugal o de las comunidades situadas en el occidente de Europa.

El triunfo de las formas aragonesas que señalamos arriba es el resultado del primer contacto directo en las nuevas comunidades del Imperio Otomano creadas inmediatamente después de 1492 entre hablantes que ha-

\footnotetext{
${ }^{\text {t10 }}$ Quintana, "Concomitancias lingüísticas...".

11 En dicho año comenzó a actuar definitivamente la Inquisición en Portugal.

112 Se trata del año en que el emperador Carlos I expulsó a los judios de los Países Bajos. Hasta veinte años más tarde no podrían los sefardies encontrar refugio en Amsterdam por formar el mencionado territorio parte de la Corona Española.

${ }^{13} \mathrm{Cfr}$. Jacob Barnai, "Los judíos del Imperio Otomano en los siglos 17 y $18 \mathrm{~m}, \mathrm{El} \mathrm{Le}$ gado de Sefarad, vol. II, editado por H. Beinart, Jerusalén, Magnes Press, 1993, pág. 142, donde menciona la desintegración del marco creado por los quehalim que en Estambul tuvo lugar a mediados del siglo xvis a raíz de los grandes incendios que se declararon en dicha ciudad.
} 
bían entrado en una situación de diglosia castellano-aragonés y hablantes monolingües castellanos. Varias de las voces o formas de origen aragonés presentes en el léxico judeoespañol se encuentran también en textos aljamiado-moriscos (<atorgar, aturar, turar, prebar, feguza, esfeguzado, lugo, abantağar, tararaña ( $=$ "araña"), eskorchar, mengrana, koda, fortuna $>$ ) ${ }^{114}$, casi todos ellos procedentes de comunidades que formaron parte del antiguo Reino de Aragón.

La llegada de los anusim portugueses abrió un nuevo ciclo en el proceso lingüístico de nivelación con el inicio de la entrada de formas portuguesas ${ }^{115}$ especialmente después de 1549 , como sucedería más tarde con la llegada de los francos desde finales del siglo XVI, sefardies procedentes de Liorna ${ }^{116}$ de los cuales algunos aún hablaban portugués, pero la mayoría de ellos se comunicaba en italiano. Todo ello se manifiesta claramente en la lengua escrita en el siglo xviII.

Como señaló Bunis ${ }^{117}$, la lengua de los sefardies otomanos contaba en el siglo XVI con varias variedades que cambiaban de acuerdo con la estratificación social y educativa del grupo. Las variedades más populares, ilustradas parcialmente en el Séfer Héšseq Šelomó, y en el Séfer S̆ulhán Hapanim, son las que más similitudes guardan con las que triunfaron en la sociedad sefardí a partir del siglo XVII, incluso ya antes. Las comunidades que se vieron menos afectadas por la crisis textil iniciada en el siglo XVII ${ }^{118}$, conservaron más elementos de la que había sido la clase dominante sefardí, al menos desde el punto de vista intelectual, a lo largo del siglo XVI, es decir, elementos propios de la norma castellana más culta. La lengua de la comunidad de Estambul es la que mejor ilustra nuestra afirmación.

A la influencia cultural ejercida desde Salónica y Estambul, se suma a partir del siglo XVII la económica y culturalmente floreciente comunidad de Esmirna. De manera que nos encontramos, de un lado, con Salónica, y las comunidades del interior de los Balcanes con las que la ciudad griega man-

\footnotetext{
114 Cfr., A. Galmés de Fuentes e.a., Glosario de voces aljamiado-moriscas, Oviedo, Universidad de Oviedo, 1994.

${ }^{115}$ El rabino Mošé Almosnino en su Livro entitulado reŷimyento dela vida (1564) emplea ya una veintena de formas portuguesas, algunas de las cuales aparecen de manera vacilante al lado de las correspondientes castellanas: <arejgádo $>$ (120v) y <arajgádo > (14v), <enlevádo> (36v) y <eleváda> (75), <eskaráá (35) y <eskupír> (ibidem), <milágre> (97, 15lv) y <nilágro> $(97,136 \mathrm{v})$ entre otras, cfr. I.S. Révah, "Le lexique...", págs. 223-225.

${ }_{116}$ E. Benbassa y A. Rodrigue, Juifs des Balkans, pág. 115.

${ }^{117}$ Bunis, «Tres formas de ladinar la Biblia...,, pág. 342.

${ }_{1 i s}$ Nos referimos una vez más a la crisis textil que produjo varios movimientos migratorios judios dentro del Imperio Otomano, especialmente de Salónica a Esmirna y de Safed a Jerusalén, como señala Jacob Barnai, «Los judíos del Imperio Otomano...», págs. [40-146.
} 
tenía estrechas relaciones comerciales. Del otro lado, estaban Estambul y Esmirna con influjo sobre las comunidades de Turquía e Israel debido a las constantes visitas a las cuatro ciudades santas y muy especialmente a Jerusalén, donde no siempre es fácil diferenciar entre formas más o menos recientes. Esto lo vemos perfectamente en la distribución de los significantes de 'sanguijuela', para lo cual remitimos una vez más al mapa, suponiendo que efectivamente la forma /sanŷwéla/, presente en las comunidades del interior de los Balcanes y también documentada en Esmirna, haya existido en el judeoespañol de Salónica, frente a la forma /sanŷigwéla/ y similares, presentes en el judeoespañol de Estambul y comunidades inmediatas (Bursa, Edirne, incluso Jerusalén).

La penetración desde finales del siglo XVI de compañías inglesas relacionadas con la industria de la lana en el Imperio Otomano no solamente había propiciado la caída de la industria textil ${ }^{119}$, hasta esos momentos en manos de ciertas familias judias que todavía mantenían una fuerte conciencia e identidad castellana, sino también el ascenso a áreas de poder e influencia de otros grupos procedentes de la clase media sefardi o de otros grupos de judíos, bizantinos principalmente o asquenasíes, pero que habian sido hispanizados desde el punto de vista de la lengua, que ahora se enriquecian trabajando para las compañías extranjeras, lo cual ocasionó a su vez el definitivo triunfo de la norma sefardí empleada por las clases populares sefardíes. La familia de Sabbatai Seví, el falso mesías, ilustra bastante bien nuestra afirmación: el padre de Sabbatai se había instalado en la próspera ciudad de Esmirna a principios del siglo xvII y se había enriquecido trabajando para las compañías inglesas ${ }^{120}$, lo mismo que aconteció con muchas otras familias sefardíes llegadas especialmente de Salónica, pero también desde Estambul y desde pequeñas comunidades del Imperio Otomano, y de origen marrano. Como Sabbatai Seví, la mayoria de los rabinos que fueron contemporáneos suyos procedian de esa nueva burguesía.

Las comunidades creadas en el siglo xviII (Bucarest, Craiova, Ruse o Varna), en las que, como en la de Esmirna, confluyeron sefardies de varios lugares, fueron protagonistas de nuevos procesos de nivelación lingüística.

119 E. Benbassa y A. Rodrigue, Huifs des Balkans, págs. 108-109.

120 E. Benbassa y A. Rodrigue, Juifs des Balkans, pág. 129. Para una amplia información sobre el carácter sociológico de la burguesía sefardi del siglo xvII a la que pertenecía el falso mesías, recomendamos los articulos de Jacob Barnai, "Los judios del Imperio Otomano...», págs. 139-170 y de R.J. Zwi Werblowski, «Šabbatai Șebi», El Legado de Sefarad, vol. II, edjtado por Haim Beinart, Jerusalén, Magnes Press, 1993, págs. 214-224, asi como la excelente obra de Gershom Scholem, Sabbatai Sevi: the mystical messiah, Princeton, Princeton Univiersity Press, 1973 editada también en otras Ienguas. 
En estos procesos de nivelación participaron ya elementos de las normas más o menos institucionalizadas en las grandes comunidades. Respecto a qué norma triunfó en ellas, un factor importante fue su mayor o menor grado de relación económica con una u otra de las comunidades ya existentes más que el propio lugar de origen de sus fundadores.

En cuanto a los adstratos (formas léxicas de las lenguas vecinas), a principios del siglo $\mathrm{xx}$ se apreciaba una ligera tendencia a la sustitución de estas formas sefardies, nos referimos a las analizadas aquí, por otras procedentes de las lenguas coterritoriales. Las formas de Castoria/sangwéta, kosterísa/ nos indican que el contacto entre el judeoespañol y las lenguas vecinas era más intenso en las pequeñas comunidades que en las grandes. Como ya mencionamos, en libros sefardíes de medicina popular aparece con frecuencia la palabra de origen turco "sulúk" (turc. <sülük>), al lado de /sanŷigwéla/ o sanbesuga, sin embargo, el lexema turco no llegó a desplazar a los lexemas de origen hispánico en ninguna de las comunidades analizadas.

\section{CONCLUSIONES}

De acuerdo con la distribución diatópica de las formas léxicas y voces analizadas, podemos concluir que se deducen procesos independientes de nivelación lingüística, tanto para las comunidades creadas inmediatamente después de 1492 (Salónica, Monastir, Estambul, Edirne y Bursa) como para las que lo fueron más tarde. En dicho proceso, con las formas y voces castellanas compitieron arcaísmos, formas y voces de uso popular y formas y voces de otras lenguas iberorrománicas llegando, algunas veces, a triunfar éstas finalmente. En otros casos, el proceso de acomodación tuvo como resultado la aparición de formas interdialectales que antes no existían en ninguno de los dialectos participantes en dicho proceso. En bastantes ocasiones, el proceso competitivo entre las formas o voces candidatas no llegó a cerrarse nunca, como se puede ver en la tabla, lo cual explica los abundantes casos de polimorfismo que se registran en todos las comunidades sefardies. En todo caso, factores socioeconómicos representaron un papel decisivo en la elección de la norma lingüística sefardi durante el siglo XVII, así como en la configuración de cada koiné y en la expansión de fenómenos lingüísticos llevados de una comunidad a otra.

Todas las variedades sefardíes, sin excepción, poseen un sistema léxico con base castellana de origen popular, desarrollado a partir de una variedad hablada por las clases media y baja del siglo XVI, compuestas por una ma- 
yoría descendiente de judíos procedentes del Reino de Castilla ${ }^{121}$. Aunque no disponemos de testimonios suficientes sobre la lengua hablada por los judíos antes de la expulsión de 1492, todo parece indicar que el carácter popular de su romances era ya un rasgo acusado que también se hallaba presente en la variedad de los moriscos. Después de 1492 la diferencia entre la composición del sistema léxico de cada una de las comunidades sefardíes radica esencialmente en la mayor o menor aceptación de voces y formas de origen iberorrománico no castellano.

121 Yosef Hacker, "Los exiliados españoles en el Imperio Otomano entre los siglos xv y xvıIn, The Sephardic Jewish Diaspora after the Expulsion from Spain, Jerusalén, The Zalman Shazar Center, 1992, págs. 27-28 [en hebreo]. 